\title{
Shifting patterns of emergency incidents during the COVID-19 pandemic in the City of Vaughan, Canada
}

\author{
Adriano O. Solis \\ Decision Sciences Area, School of Administrative Studies, York University, Toronto, Canada \\ Janithra Wimaladasa and Ali Asgary \\ Disaster and Emergency Management Program, School of Administrative Studies, York \\ University, Toronto, Canada \\ Maryam Shafiei Sabet \\ Fleming College - Sutherland Campus, Peterborough, Canada \\ Michael Ing \\ Vaughan Fire and Rescue Service, Vaughan, Canada \\ Accepted for publication in the International Journal of Emergency Services, \\ DOI: 10.1108/IJES-05-2021-0024) \\ https:/www.emerald.com/insight/content/doi/10.1108/IJES-05-2021-0024/full/html \\ Author Accepted Manuscript (AAM) is attached.
}

This research has been conducted with financial support from the Social Sciences and Humanities

Research Council of Canada (SSHRC) as part of its Partnership Engage Grants (PEG) COVID-19 Special Initiative.

The Vaughan Fire and Rescue Service is the partner organization of the York University research team in this effort. 


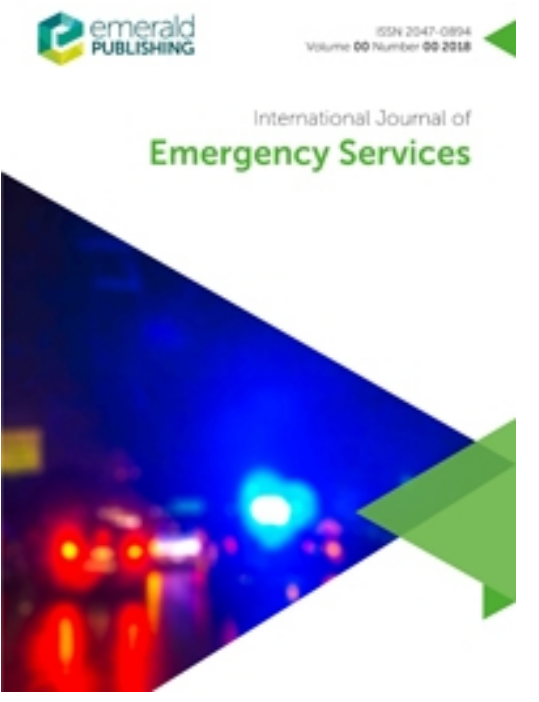

\section{Shifting patterns of emergency incidents during the COVID- 19 pandemic in the City of Vaughan, Canada}

\begin{tabular}{|r|l|}
\hline Journal: & International Journal of Emergency Services \\
\hline Manuscript ID & IJES-05-2021-0024.R1 \\
\hline Manuscript Type: & Research Paper \\
\hline Keywords: & $\begin{array}{l}\text { COVID-19, pandemic, emergency incidents, temporal analysis, City of } \\
\text { Vaughan, Fire and Rescue Service }\end{array}$ \\
\hline
\end{tabular}

\section{SCHOLARONE \\ Manuscripts}




\title{
Shifting patterns of emergency incidents during the COVID-19 pandemic in the City of Vaughan, Canada
}

\begin{abstract}
Purpose - The COVID-19 pandemic has changed many facets of urban life and operations, including emergency incidents. This study examines how COVID-19 has brought about changes in, and shifting patterns of, emergency incidents in the City of Vaughan, Ontario, Canada. The study aims to derive insights that could potentially inform planning and decision-making of fire and rescue service operations as further stages of the pandemic unfold.
\end{abstract}

Design/methodology/approach - Standard temporal analysis methods are applied to investigate changes in number and nature of emergency incidents, as recorded sequentially in the city's fire and rescue service incident report database, through various phases or waves of the pandemic and the associated public health measures that have been introduced.

Findings - Our analyses show a decrease in the number of emergency calls compared to previous reference years. Vehicle related incidents show the highest decline, and changes in daily and hourly pattens are consistent with public health measures in place during each stage of the pandemic. The study concludes that the COVID-19 pandemic has had significant impact on demand for emergency services provided by the fire department.

Originality/value - We believe this is the first study applying temporal analysis on a city's emergency incident response data spanning various phases/waves of the COVID-19 pandemic. The analysis may be replicated for other municipal fire services, which can generate further insights that may apply to specific local conditions and states of the pandemic.

Keywords: COVID-19, pandemic, emergency incidents, temporal analysis, City of Vaughan, fire and rescue service 


\section{Paper type: Research paper}

\section{Introduction and Background}

COVID-19, the disease caused by the SARS-CoV-2 novel coronavirus and its variants, continues to spread all over the world, as well as throughout Canada's ten provinces and three territories. The first known case in Canada was reported on 25 January 2020 in the city of Toronto, province of Ontario (Reuters, 2020; Global News, 2020a). The provincial government of Ontario declared a state of emergency on 17 March 2020 (Province of Ontario, 2020a), which was followed by a number of public health measures intended to control the pandemic during different stages.

The COVID-19 pandemic has brought about unprecedented challenges worldwide, the likes and magnitudes of which have not heretofore been experienced. Governments and their agencies at all levels (federal/national, provincial/territorial, and municipal/local) have had to formulate and implement, largely without the benefit of prior experience with these COVID-19 challenges, socioeconomic, health and other measures to address a "new normal" that has arisen in citizens' lives.

In this study, we evaluate emergency incident and response patterns/performance in the City of Vaughan, Ontario, under the ongoing COVID-19 crisis and compare them with those during the preceding three years before the pandemic came about. We investigate emergency incidents and responses, taking into consideration incident/response attributes (e.g., incident types, locations, property types, among others). We believe this to be the first study comparing fire and rescue service operations prior to and during the ongoing COVID-19 pandemic. We seek to provide insights that may inform decision-makers in identifying appropriate levels and allocation of resources (firefighting apparatus and firefighters) across the existing fire stations. This study contributes to existing literature by way of data analytics that may be relevant to evidence-based decision-making for subsequent stages/waves of COVID-19, as well as similar future pandemics. 
Earlier, Shafiei Sabet et al. (2019) conducted spatiotemporal analyses of emergency incidents and responses that occurred in the City of Vaughan during the 2013 ice storm in Southern Ontario, with 20-31 December 2013 as the 'study period'. Incident and response patterns were compared with those arising in the same 11 calendar day period in other years (2009-2012 and 2014-2016). In the current study, we undertake temporal analyses of data for the COVID-19 pandemic covering almost ten months (from 17 March 2020 to 13 January 2021), in comparison with data for the corresponding time periods during the three preceding years.

Seventeen years before the COVID-19 pandemic was declared, there had been an outbreak in 2003 of Severe Acute Respiratory Syndrome (SARS), a disease caused by the original SARS coronavirus SCoV, primarily in the Greater Toronto Area (Low, 2004; Public Health Agency of Canada, 2004). On March 26, 2003, with 18 cases of SARS reported in the province of Ontario as of the day before, the Premier of Ontario declared SARS to be a provincial emergency (Public Health Agency of Canada). Altogether, over the less than six months since the first case of SARS arrived in Toronto in the last week of February 2003 until the last patient was discharged from hospital in early July 2003, there were a total of 375 cases and 44 deaths recorded in Ontario (Low, 2004; Ontario Ministry of Health, 2021). Emergency incident data for the City of Vaughan during the SARS outbreak in 2003 is not readily accessible, but one can wonder how that outbreak may have affected the city's first response operations.

In comparison, as of 13 January 2021 there had been a total of 228,310 COVID-19 cases (with 193,814 resolved) and 5,189 deaths in the province of Ontario (Public Health Ontario, 2021). The stark contrast between the numbers of SARS and COVID-19 cases and deaths would suggest perhaps a far more significant impact of COVID-19 on emergency incidents in the City of Vaughan 
and its fire and rescue service operations. This paper reports on our temporal analyses and findings pertaining to such impact during the first 10 months of the COVID-19 pandemic.

\section{Dataset and Methods}

\subsection{City of Vaughan and Emergency Incident Dataset}

The City of Vaughan, situated north of the City of Toronto (Figure 1), is one of nine municipalities in the Regional Municipality of York (also known as York Region) of the Canadian province of Ontario. Vaughan is part of what is referred to as the Greater Toronto Area (GTA), which includes the city of Toronto and cities/towns located in the four regional municipalities of York, Peel, Halton, and Durham (Wikipedia, 2021). Vaughan has an estimated current population of 335,000 (City of Vaughan, 2021a). The Vaughn Fire and Rescue Service (VFRS) operates with ten fire districts, Districts 71, 72, .., 79, 710, with corresponding Fire Stations 7-1, 7-2, .., 7-9, 7-10, respectively (Figure 2).

Figure 1 and Figure 2 about here

VFRS provided the dataset of all occurrences of incidents within the City of Vaughan that it has responded to until 13 January 2021. As with all other fire departments in the province of Ontario, the VFRS is required to prepare, and record in its operations database, a Standard Incident Report (SIR) for every response to an emergency incident. Included in the SIR dataset are various incident and response attributes, including incident number, latitude, longitude, district, station, incident/response type (e.g., fire, alarm system equipment malfunction or accidental activation, carbon monoxide incident or false alarm, vehicle collision, medical calls of various types, etc.), dispatch date and time, responding unit arrival date and time, clearing date and time, and property 
type. An SIR Codes List, issued by the Office of the Fire Marshal of Ontario (2009), specifies codes for response types, property types, and certain other major incident attributes.

Access to the VFRS incident dataset since more than ten years back had been made available to the research team. However, for purposes of the current study, only data starting from 17 March 2017 has been analyzed, enabling comparison of periods during the pandemic with corresponding periods in the three preceding years. Incident data during the pandemic were provided incrementally, after the end of each period of the pandemic. The dataset was divided according to reference periods during the COVID-19 pandemic. We examine the emergency incidents that occurred during the first six periods of the pandemic relevant to the city of Vaughan, spanning a total of 303 calendar days from 17 March 2020, when a provincial state of emergency was first declared by the government of Ontario (Province of Ontario, 2020a), until 13 January 2021, the day before a second state of emergency came into effect (Province of Ontario, 2021).

\subsection{Reference Periods}

For purposes of our study, we use the following reference periods:

- Period 1: 17 March - 18 May 2020 (State of Emergency I - 63 calendar days)

○ Period 2: 19 May - 18 June 2020 (Stage 1 of reopening of the economy - 31 calendar days)

- Period 3: 19 June - 23 July 2020 (Stage 2 of reopening of the economy - 35 calendar days)

- Period 4: 24 July - 18 October 2020 (Stage 3 of reopening of the economy -87 calendar days)

- Period 5: 19 October - 13 December 2020 (Modified Stage 2 of reopening of the economy -56 calendar days) 
○ Period 6: 14 December 2020 - 13 January 2021 ('Lockdown' - 31 calendar days)

The reference dates as specified for Periods 2-5 are associated with stages of reopening of the economy applying to York Region (Province of Ontario, 2020b, 2020c, 2020d). Period 6 pertains to York Region being placed in the Grey lockdown zone (York Region, 2020; Global News 2020b) of the Keeping Ontario Safe and Open COVID-19 Response Framework (Province of Ontario, 2020e).

\subsection{Temporal Analyses}

The analysis of data as reported in this paper was carried out principally applying temporal analyses of emergency incidents and responses, to identify response patterns during the six periods of the pandemic as specified above, and comparing them with corresponding periods under 'normal' conditions (during the three years preceding the COVID-19 pandemic).

Temporal analyses are used to examine the relative trends of incidents across time (Wuschke et al., 2013). Vasiliev (1997) investigated how temporal information on geographic data could be represented according to five categories: (i) moments, (ii) duration, (iii) structured time, (iv) time as distance, and (v) space as clock. Boldt and Borg (2016) added a sixth time representation: (vi) time span ("a duration in which a moment or a duration could have taken place, but one is unsure about the specifics"). In this paper, we only report on the first three categories - moments (e.g., emergency alarm times), duration (e.g., response times) and structured time (e.g., days and hours of emergency calls, as well as daytime vs. nighttime hours). The categories of 'time as distance' (the measurement of how far it would be possible to travel within a duration of time) and 'space as clock' (used to depict how an area changes over time) fall under the spatiotemporal type of analyses, which are not covered in the current paper. The 'time span' category, as defined by Boldt and Borg (2016), would apply to a crime, such as a burglary or homicide, where the actual moment 
or duration of crime occurrence may not be known with certainty. However, this time span category is not relevant in our case, in view of alarm times/dates and other information on emergency incidents as recorded in the VFRS incident dataset.

Choosing a suitable analysis method is important, as the choice of method affects the end results (Boldt and Borg, 2016) and, thereby, affects the actions or recommendations based on the analysis. Temporal analyses can be carried out using various temporal resolutions such as hours and days, as well as other time periods (such as Periods 1-6 in the current case), and appropriate temporal resolutions will provide immense insights about data.

For our temporal analyses, we undertake statistical analyses across Periods 1-6, and the days and hours in each period, using primarily alarm date and alarm time information recorded in the dataset to establish days and hours of occurrence of emergency incidents. We primarily use line/bar charts and circular time plots (see, for instance, Asgary et al., 2010; Wuschke et al., 2013; Santos, 2017; Shafiei Sabet et al., 2019) to illustrate similarities, differences, and emerging patterns over time.

\section{Findings}

The analyses were carried out considering the overall number of incidents and, for selected incident/response types of interest such as medical emergencies, vehicle collisions/extrications, and false fire calls, considering frequencies of occurrence of such emergency incidents and their potential impact on VFRS operations during the COVID-19 pandemic. We also present the patterns in response times before and during the pandemic.

\subsection{Overall Emergency Incidents}

Overall, the results show that, for each of the six periods, the total number of incidents was always less during the COVID-19 year than the number during the corresponding period of the previous year or the average number over the preceding three years (Table I and Figure 3). The 1,476 
emergency incidents overall in Period 1 represented a decrease of 345 (close to $19 \% \downarrow$ ) relative to the 1,821 incidents in the same period in 2019 , or a decrease of 446 incidents $(23 \% \downarrow)$ compared with the average of 1,922 incidents for the same period in 2017-2019 (Table I). This decline in the overall number of incidents would appear to be consistent with the 'lockdown' in Period 1 of all non-essential establishments, as mandated by the provincial government, and the recommendation for people to stay home except when necessary.

Table I about here

Figure 3 about here

The aggregate and average daily numbers of emergency incidents in Periods 1 through 6 of the COVID-19 pandemic, in comparison with corresponding numbers during the previous year, are summarized in Table II. For each period, as well as for Periods 1-6 overall, the daily mean number of emergency incidents for the COVID-19 year was always less than in the previous year. In Period 1, the test of equality of variances (COVID-19 year versus previous year) was highly significant, with $\mathrm{p}$-value $=0.0133$ for the one-tailed $F$-test. Each of Periods 2 through 6 , as well as Periods 1 6 overall, however, yielded an insignificant $F$-test of equality of variances. The right-hand-tailed $t$-test of difference between daily means for corresponding periods of the previous year and of the COVID-19 year was either significant or highly significant for each period: significant for Periods 2, 5, and 6; and highly significant for Periods 1, 3, and 4, as well as Periods 1-6 overall (p-values are reported in Table II). 


\section{Table II about here}

The daily pattern of emergency incidents in Period 1 of the COVID-19 pandemic (Figure 4a) shows that daily numbers of incidents were, except for a few exceptions, less than corresponding daily numbers in the same period in 2019. Similar patterns are observed for Periods 2 and 3 (Figures $4 \mathrm{~b}$ and $4 \mathrm{c}$, respectively). The pattern changes in Periods 4 and 5 (Figures $4 \mathrm{~d}$ and $4 \mathrm{e}$, respectively). However, the comparison seems to re-emerge in Figure 4f, which pertains to Period 6 when another lockdown was in place.

\section{Figure 4 about here}

To examine the hourly patterns of emergency incidents we have created a number of circular time plots (Figure 5). Results show that during Period 1 (Figure 5a), a noticeable decrease in the average hourly numbers of responses can be identified from 8:00 a.m. to 8:00 p.m., when compared with the corresponding numbers in 2019 and average numbers over the preceding three years (20172019). This appears to be consistent with the declaration on March 17, 2020 of a provincial state of emergency under which non-essential establishments were closed down and residents were advised to stay home. For each of Periods 1-6, in fact, the left-hand-tailed $t$-test of paired differences between hourly means showed a highly significant decrease (with $p$-value $<0.01$ ) from the average of the preceding three years to the COVID-19 year. A visual comparison among the six circular temporal plots in Figure 5 indicates the most substantial decreases in hourly mean emergency incident frequencies to have arisen in Period 1. 
Figure 5 about here

\subsection{Emergency Incidents by Property Type}

Property type refers to the use made of a structure, portion of a structure, vehicle or outside area by an owner, tenant, or occupant of a space (Office of the Fire Marshal of Ontario, 2013). Property types are classified into eight groups as follows: (A) Assembly; (B) Care and Detention; (C) Residential; (D) Business and Personal Services; (E) Mercantile; (F) Industrial; (G) Structures/Properties not classified by the Ontario Building Code; and (H) Vehicles (Office of the Fire Marshal of Ontario, 2009).

Figures $6 \mathrm{a}$ to $6 \mathrm{f}$ show that Residential properties (type C) accounted for much higher percentages of emergency incidents overall - between $59.4 \%$ and $71.5 \%$ during the pandemic, compared with average shares of only between $52.5 \%$ and $57.1 \%$ during the preceding three years. In particular, the high of $71.5 \%$ share for residential properties occurred during Period 1 of the pandemic, increasing by 18.3 percentage points over the $53.2 \%$ average share in the preceding three years (Figure 6a). It ought to be pointed out, however, that there were no truly substantial increases in absolute numbers of incidents occurring in residential properties. For instance, in Period 1 (see Table III) the total number of emergency incidents occurring in residential properties increased to 1,055 compared to $991(6.5 \% \uparrow)$ during the same period in 2019 and compared to an average of $1,020(3.4 \% \uparrow)$ in the preceding three years (2017-2019). This situation - in which the percentage share of incidents in residential properties increased by double digits while the actual number of such incidents did not increase as much - arose in view of substantial reductions in numbers of incidents occurring in other property types, e.g., Vehicles (type H) and Assembly (type A). 
In Periods 2 to 6 (Figures $6 \mathrm{~b}$ to $6 \mathrm{f}$, respectively), the shares of residential properties in total emergency incidents increased by between 6.9 and 10.9 percentage points, with the increase of 10.9 percentage points occurring during the lockdown in Period 6.

Figures 6(a) to 6(f) about here

Table III about here

Figures $6 a$ to $6 \mathrm{f}$ show that, in contrast with residential properties' percentage shares of total incidents which increased in each period, the percentage share of Vehicles (Group H) dropped in every single period. Shares of vehicles in Periods 1-6 of the pandemic were between $7.9 \%$ and $13.8 \%$, versus average shares of between $15.6 \%$ and $18.9 \%$ in the preceding three years. The decreases in percentage shares of vehicles ranged between 3.8 and 7.7 percentage points. The largest decrease of 7.7 percentage points occurred in Period 1, when vehicles accounted for only $7.9 \%$ of all emergency incidents compared with an average of $15.6 \%$ in the same period during the preceding three years (2017-2019). This significant decrease in share of vehicles to total incidents, in fact, is associated with a $61 \%$ drop in the number of incidents occurring in vehicles to only 117 (an average of only 1.9 incidents per day) in Period 1 from an average of 299 (or an average of 4.7 incidents per day) in the same period during 2017-2019.

\subsection{Medical Emergencies}

In Period 1 of the pandemic, medical emergencies accounted for $50.9 \%$ of all incidents (752 of 1,476 ), versus $46.4 \%$ on average in the same period in $2017-2019$ (refer to Table IV). For Periods 
1-6 overall, the 4,074 medical emergencies accounted for $49.5 \%$ of the 8,225 total emergency incidents (versus an average of $45.5 \%$ in the same six-period time intervals during the preceding three years). In absolute terms, however, the number of such incidents actually went down by 287 $(6.6 \% \downarrow)$ from an average of 4,361 in the preceding three years.

Table IV about here

In Period 1, there was a $15.7 \%$ drop in medical emergencies from 14.2 average per day to 11.9 per day during the pandemic. The decrease in medical emergencies in Period 1 arose mainly from three incident types: chest pains or suspected heart attack (down by 84 from a 2017-2019 average of $139(60 \% \downarrow)$ during the same period), other medical/resuscitator call (down 72 from an average of $181(40 \% \downarrow)$ ), and oxygen administered (down to just 3 from an average of 37). There was, however, an increase in incidents of type 898 (medical/resuscitator call, no action required) to 421 from a 2017-2019 average of $318(32 \% \uparrow)$, which may likely be attributed to what were reported as COVID-19 positive screens.

In Period 2, 47.9\% of all incidents were medical emergencies, which is comparable with $46.6 \%$ in the same period in 2017-2019. The total number of medical emergencies, in absolute terms, declined to only 418 in Period 2 from an average of $472(11.4 \% \downarrow)$ in 2017-2019. In Period 3, medical emergencies dropped in number to only 411 from an average of 484 (slightly over $15 \%$ $\downarrow)$ in the same period in 2017-2019. More than half of the decrease in medical emergencies in Period 3 again arose from fewer recorded occurrences of incident type chest pains or suspected heart attack. 
The comparisons in Periods 4 and 5 were not as remarkable, however, with relatively smaller decreases in absolute numbers of medical emergencies (only 3.5\% $\downarrow$ in Period 4 and $0.2 \% \downarrow$ in Period 5). What is perhaps notable is an increase in number of incidents in Period 6 to 518 from an average of $494(4.8 \% \uparrow)$ during the same period in the preceding three years. A declared lockdown in Period 6, at the start of the winter season, may have led some ailing residents to call emergency services instead of proceeding to emergency rooms or medical clinics themselves.

In the circular time plots showing distributions of medical emergencies over 24 hours (Figure 7), decreases in hourly mean incident frequencies during COVID-19 are visually observable overall in Periods 1 and 3 compared to the averages in the same periods during the three preceding years. In fact, highly significant left-hand-tailed $t$-tests of paired differences between hourly averages (during the COVID-19 period versus the corresponding period in the preceding three years) arise for these two periods, with $\mathrm{p}$-value $<0.01$. The one-tailed $t$-test is significant for Period 2 ( $\mathrm{p}$-value $=0.046)$. The tests of differences between hourly means are not significant for Periods 4, 5, and 6 .

Figure 7 about here

An examination of medical emergencies by property type in Period 1 (see Table V) reveals that, with the initial declaration of a COVID-19 state of emergency within the city, there were considerable decreases in incidents occurring in properties within Groups A (assembly), B (care and detention), D (business and personal services), E (mercantile,) F (industrial), and H (vehicles).

Table $\mathbf{V}$ about here 
Daily average numbers of medical emergency incidents were consistently lower for Periods 1-6 compared with daily averages for corresponding periods in the preceding three years for assembly (Figure 8a), business and personal services (Figure 8d), and mercantile (Figure 8e) property types. The lower daily averages during Periods 1-6 of the pandemic (versus averages during the preceding three years) would appear to be consistent with restrictions imposed on sizes of indoor gatherings as well as shutdowns of non-essential business establishments. Daily averages of medical emergencies occurring in vehicles (Figure $8 \mathrm{~b}$ ) were also generally lower during the pandemic, except in Period 5. On the other hand, average numbers of medical emergencies per day reported in residential properties (Figure 8c) considerably increased in Periods 4-6 in comparison with averages for corresponding periods in the preceding three years. We find no apparent explanation for this increase, however.

Figure 8 about here

\subsection{Vehicle Collisions/Extrications}

Incidents of vehicle collision/extrication declined quite dramatically in each of Periods 1-6 of the COVID-19 pandemic compared to the average number of such incidents during the corresponding period in the preceding three years (Table VI and Figure 9). The vehicle collision/extrication incidents decreased by $69 \%$ in Period 1 compared with the pre-pandemic period, with average daily incidents dropping from 4 per day in 2017-2019 down to only 1.2 per day in 2020 . The substantial drop in Period 1 in vehicle collision/extrication incidents appears consistent with the expectation for citizens to stay home, and to leave home only when necessary, in view of the 'lockdown' imposed under the declaration of a state of emergency in the province of Ontario. The 
decrease of 176 incidents from 254 to 78 over the 63 days in Period 1 was the largest contributor to the overall decline of 446 incidents in this period to only 1,476 total incidents from the preceding 3-year average of 1,922 (refer to Table I). In fact, the vehicle collision/ extrication incident category was consistently the largest contributor to the decrease in total emergency incidents in each of Periods 1-6. In Period 2, there was a total of 78 vehicle collision/extrication incidents over 31 days. This represented a smaller reduction $(46 \% \downarrow)$ from the average of 144 incidents in the same period in the preceding three years. Following a limited economic reopening (Stage 1), the average of 2.5 incidents per day in Period 2 was just over double that in Period 1, but still below the average of 4.6 per day in the same period in 2017-2019.

Table VI about here

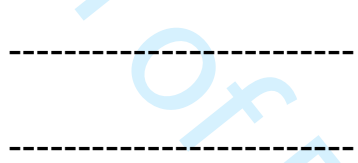

Figure 9 about here

Even with the further economic reopening (Stage 2) during Period 3, there were only 83 vehicle collision/extrication incidents, representing a notable decrease $(53 \% \downarrow)$ from the average of 177 incidents in the same period in 2017-2019. The average of 2.4 incidents per day was double the daily average in Period 1, but less than half the 5.1 daily average over the same period in the preceding three years. Despite reopening of the economy, there was still a drop by slightly more than one-third in vehicle collision/extrication incidents (just over 34\% $\downarrow$ ) in Period 4.

The overall reduction (almost $48 \% \downarrow$ ) to a total of 747 vehicle collision/extrication incidents (or only about 2.5 incidents per day) across all six periods, versus an average of $1,432.7$ in the 
preceding three years (or about 4.7 incidents per day), appears to be indicative of a shifting pattern as a relatively large proportion of the population continued to stay at, or work/study from, home. The renewed lockdown in Period 6, as expected, once again led to a large decrease (close to 59\% $\downarrow$ ), overshadowed only by the $69 \%$ drop in Period 1 .

In the circular temporal plots of average numbers of vehicle collision/extrication incidents for all six periods under study (Figure 10), there are apparent overall decreases in average numbers of incidents - particularly during the daytime hours. For every single period under study, the $t$-test of the paired differences between hourly averages (for the preceding three years versus the COVID19 year) is highly significant, with p-value $<0.01$ for each period. This is consistent with lower numbers of vehicles being on the road during the COVID-19 pandemic. The largest visually observable, and most dramatic, decreases in hourly average numbers of vehicle collision/extrication incidents occurred in Period 1, following the initial declaration of a provincewide State of Emergency - when citizens were originally ordered to stay home, and all nonessential establishments were shut down.

\section{Figure 10 about here}

\subsection{False Fire Calls}

False fire calls constitute another incident category of interest. This category includes calls related to the following response type codes: 31 - alarm system equipment malfunction; 32 - alarm system equipment accidental activation; 33 - human malicious intent/prank; 34 - human perceived emergency; 35 - alarm accidentally activated by person; and 39 - other false fire calls (Office of 
the Fire Marshal of Ontario, 2009). Table VII summarizes the numbers of false fire calls in each of the six periods under study.

\section{Table VII about here}

False fire calls show a drop in Period 1 to 205 from an average of $322(36 \% \downarrow)$ in the same period in 2017-2019. The average number of false fire calls decreased to 3.25 per calendar day in Period 1 from an average of 5.1 per day in the same period in 2017-2019. Among others, alarm system equipment malfunctions (incident type 31 ) and accidental activations (type 32 ) dropped to only a total of 99 in Period 1 from 147 such incidents $(33 \% \downarrow)$ in the same period in 2019 . The number of accidental alarm system activations by a person (type 35) decreased to only 36 incidents in Period 1 compared to 66 such incidents $(45 \% \downarrow)$ in the same period in 2019 . The last cited decrease appears to be consistent with accidental activations by humans being less likely to occur if people do not leave their residences or do not enter places of work.

However, following the limited economic reopening in Period 2 (Stage 1), there were a total of 132 false fire calls during the 31 days in Period 2 (or an average of 4.3 such incidents per day), not too different from the average of 138 in the same period (or an average of 4.5 per day) in the preceding three years. With the further reopening of the economy in Period 3 (Stage 2), the frequency of false fire calls (195 incidents) had returned to pre-COVID-19 levels (an average of 189 in the same period in 2017-2019). With the renewed 'lockdown' in Period 6, there was a 39\% decrease to only 99 false fire calls (or an average of 3.2 per day) from an average of 163 such incidents (an average of 5.3 per day) during the same period in the preceding three years. Overall, 
in Periods 1-6, there was a $17.6 \%$ decrease to an average of 4.2 false fire calls per day from an average of 5.1 per day over the same periods in the preceding three years.

The circular time patterns in Figures 11a to $11 \mathrm{f}$ show the average hourly numbers of false fire calls during Periods 1 to 6 , respectively. The circular time plots of hourly average numbers of false fire calls for Periods 1 and 6, in Figures 11a and 11f, respectively, visually suggest the least hourly numbers of incidents in these two periods, compared to the same periods in the three preceding years, as well as compared to the other periods (Periods 2-5). The time plots for Periods 1 and 6 exhibit overall smaller average hourly numbers of false fire call incidents during the COVID-19 pandemic compared to the preceding three years. In this connection, it may be worth noting that Periods 1 and 6 involved lockdowns of non-essential establishments, as well as people being advised to stay home. Actually, left-hand-tailed $t$-tests of paired differences between hourly averages, during the COVID-19 period versus averages during the same period over the three preceding years, are highly significant for Periods 1,4 , and 6 , with p-value $<0.01$ in these three periods. The test is significant for Period 5, with $p$-value $=0.04$. However, the one-tailed t-tests are not significant for Periods 2 and 3.

Figure 11 about here

\subsection{Controlled Burning}

Controlled burning incidents do not normally account for a significant percentage of VFRS incidents. We briefly report here on these incidents in view of clearly observable increases in frequency in Periods 1 and 2 during the COVID-19 pandemic (see Table VIII). The number of controlled burning incidents rose to $54(149 \% \uparrow)$ during Period 1 compared to an average 
frequency of less than 22 such incidents during the same period in the preceding three years. This meant close to one controlled burning incident on average per day over the 63 calendar days in Period 1 of the pandemic. This sharp increase in controlled burning incidents, reported on residential properties, had mostly been attributed to yard waste not being collected as regularly by a city contractor in view of COVID-19, which apparently led to residents burning yard waste in their own backyards. The situation persisted into Period 2, however, with a total of 45 incidents or an average of 1.5 incidents per day $(187 \% \uparrow)$, compared with between 14 and 17 incidents (averaging only 0.5 incident per day) during the same period in 2017-2019. The frequency of controlled burning incidents appears to have 'normalized' starting in Period 3, when there were only 23 recorded incidents compared with an average of 17 incidents (between 12 and 23) in the same period during the preceding three years.

\section{Table VIII about here}

\subsection{Property Fires/Explosions}

A summary of property fire and explosion incidents during the six periods under study is presented in Table IX. Overall, the daily average number of property fires/explosions remained at roughly 0.8 incident per day, with the total number of incidents showing a very small percentage decrease $(4.3 \% \downarrow)$, during the six pandemic periods compared with the corresponding periods in the preceding three years. No emerging pattern is discernible from period to period, as the percentage changes are very different across periods. Period 6 (a lockdown period) shows the highest percentage reduction $(36.4 \% \downarrow)$ in property fire/explosion incidents. While Period 3 (Stage 2 of reopening of the economy) shows a $27.4 \%$ increase in incidents compared to the same period in 
the preceding three years, there were decreases during other stages of economic reopening (e.g., 14.3\% $\downarrow$ in Period 2 and 12.5\% $\downarrow$ in Period 5).

Table IX about here

\subsection{Response Times}

We define 'response time' for each incident to be the amount of time between when the alarm is received at the VFRS communications centre and when the first responding unit arrives at the scene of the incident. (Both time stamps are recorded in the incident dataset.) Figure 12 shows the average response time for each period of the pandemic alongside the average response time in the same period during the previous year, as well as the average in the same period over the preceding three years. No pattern could be identified in comparing average response times period-to-period during the COVID-19 year versus the previous year or versus the preceding three years.

Figure 12 about here

The average response times were also calculated separately for daytime hours (between 6:00:00 a.m. and 5:59:59 p.m.) and nighttime hours (between 6:00:00 p.m. and 5:59:59 a.m.). Average response times during daytime hours (Figure 13) from period to period as well show no pattern when compared to the corresponding period during the preceding three years. However, except in the case of Period 2, the daytime average response times during the COVID-19 year have been lower than in the same period during the previous year. There is no apparent explanation for this, though. 


\title{
Figure 13 about here
}

\begin{abstract}
$(2)$
The nighttime average response times during the COVID-19 year were consistently higher, from period to period, when compared with the previous year or with the average over the preceding three years (Figure 14).
\end{abstract}

\section{Figure 14 about here}

A similar pattern (as that observed in Figure 14) arose when we considered only average response times to medical emergencies during nighttime hours - with average response time in each period of the COVID-19 pandemic also being consistently above that in the same period of the previous year and the average during the preceding three years (refer to Figure 15). In fact, the increases in average response times during the COVID-19 pandemic were greater for medical emergencies than for emergency incidents in general. The pattern observed with respect to average response times for medical emergencies (as seen in Figure 15) did not exist, however, for non-medical emergencies (refer to Figure 16). Initially, we suspected that, in the case of medical emergency calls, the average call processing time (i.e., the time interval from receipt of the emergency call at the VFRS communications centre to receipt of the call at the fire station) was on average longer during periods of the pandemic. This was brought about by a belief that the dispatcher at the VFRS communications centre would, for the protection of responding crew members, spend more time during the pandemic inquiring on particulars of the nature of a medical emergency call as well as asking some standard COVID-19 screening questions. When we analyzed average call processing 
times, however, we did not see any pattern of consistent increases arising in the COVID-19 pandemic periods. Accordingly, the only plausible explanation we could offer behind the longer average response times during the pandemic (as observed in Figure 15) would be longer preparation times associated with protecting first responders to medical emergencies - e.g., putting on personal protective equipment - before rolling out of the fire station.

Figure 15 about here

Figure 16 about here

We observe in Figure 17 that average response times for medical emergencies on a 24-hour basis are as well higher in each period than in corresponding periods in the previous year and in the preceding three years (on average). However, the 24-hour average response times for medical emergencies, as with the increases over the preceding years' averages, are all lower than the nighttime averages during the pandemic. The longer nighttime versus 24-hour average response times may arise as a result of responding units being expected to take longer to travel to, and locate an, incident location at nighttime - whether during a pandemic or not. On the other hand, a possible explanatory factor for the overall larger increases in average response times (with respect to nighttime versus 24-hour averages) from period to period during the COVID-19 pandemic may be a heightened consciousness on the part of first responders to be better protected from exposure to the Coronavirus especially at nighttime, when visibility is not as good as during the daytime. 


\section{Figure 17 about here}

\section{Discussion}

Most disasters and emergencies, such as earthquakes, flooding, wildfires, ice storms, hurricanes, and industrial accidents, create situations where demand for emergency services increases (Asgary et al., 2018; Shafiei Sabet et al., 2019). This sudden increase in demand can not be easily and quickly met and, as such, the response time may be expected to increase due to the lack of appropriate/adequate resources or sometimes inaccessibility of the emergency site due to the ongoing conditions. In the case of a pandemic, the patterns of emergency calls are very different from other emergencies.

We examined emergency incident patterns for the City of Vaughan during the first 10 months of the COVID-19 pandemic, covering a total of 303 calendar days from 17 March 2020 to 13 January 2021 and cutting across six reference pandemic periods associated with varying public health restrictions. The findings show significant changes and pattern shifts in both the number of emergency incidents and their distributions among different incident/response types, times, and pandemic periods. Overall, the number of incidents has dropped across the board, but certain types of emergency calls, particularly vehicular incidents (collisions/extrications), show significant decreases in frequency (Figure 18). Evidently, much of these changes are attributed to the COVID19 pandemic and public health measures implemented during its various stages. Implementation of physical distancing, closure of non-essential activities, and work/study from home policies have contributed to these changes. As shown in Figure 18, there seems to be a close relationship between decreases in number of incidents and the public health measures introduced during different 
phases. For example, the largest reductions are associated with lockdown measures in Periods 1 and 6.

\section{Figure 18 about here}

As well, the distribution of emergency incidents according to response type has changed during the COVID-19 pandemic in comparison with the average distribution over the same six periods in the preceding three years. In particular, the share of vehicle collisions/extrications, has decreased to only $9.1 \%$ of all incidents in Periods $1-6$ of the pandemic from an average share of $14.9 \%$ during the corresponding periods in the preceding three years (Figure 19). VFRS' emergency response protocol provides for 1, 2, or 4 responding units (firefighting apparatus and crew members) dispatched depending upon the incident/response type, although the actual numbers dispatched may vary from the specified number depending upon actual field conditions. Solis et al. (2019) reported that, in the eight-year period from 2009 to 2016, a single responding unit was actually dispatched to $69.4 \%$ of all incidents (accounting for only $45 \%$ of the total number of responding units dispatched), while two responding units were dispatched to $20.3 \%$ of all incidents (accounting for $26.4 \%$ of responding units). Consequently, drops in both frequency and share of major response types like vehicle collisions/extrications - which require two responding units as per emergency response protocol - would clearly have implications on the use of VFRS' responding units and related resources. 


\section{Figure 19 about here}

This study provides some insights on emergency incident patterns arising during the COVID-19 pandemic in a midsized city in Canada. It would be interesting to examine these patterns in different cities in terms of size and location to further understand the impacts of the pandemic on emergency calls.

This study focused on basic statistical and temporal analyses of emergency incidents. More detailed analysis using more sophisticated analytical techniques, including some measurements of stringency of public health measures, can be conducted to further discover the relationship between incidents and public health measures. Moreover, understanding the spatial and spatiotemporal patterns of emergency incidents during the pandemic would provide further insights. Our next work will focus on this aspect of emergency calls. A subsequent paper reporting on spatial analyses and spatiotemporal analyses (e.g., Cusimano et al., 2007; Ceyhan et al., 2013; Špatenková and Virrantaus, 2013; Guldåker and Hallin, 2014; Marco et al., 2017; Liu et al., 2018; Low et al., 2018; Bringula and Balahadia, 2019; Chhetri et al., 2018; Yoo et al., 2018; Elia et al., 2019; Tang et al., 2019; Xia et al., 2019) that we are also conducting on the same VFRS incident dataset will be submitted hereafter.

Meanwhile, while this study covers a wide range of COVID-19 pandemic periods with various public health measures introduced by government authorities, there is still much uncertainty with respect to the future of the pandemic. As such, we plan to continue our research work for future periods and until the pandemic ends. 
It is important to note that this study only covers the emergency calls dispatched to the VFRS, but does not include medical emergencies in Vaughan that may have been responded to by York Region's Paramedic Services (York Region, 2021).

\section{Conclusion}

Through analysis of the incident dataset of VFRS during various phases of the ongoing COVID19 pandemic (specifically six periods covering a total of 303 days from 17 March 2020 to 13 January 2021), this study has exhibited how the pandemic can change the frequencies and patterns of various types of emergency incidents alongside public health measures/ restrictions that are introduced by government authorities to help prevent the unmitigated spread of the disease.

The overall reduction in emergency calls, especially during periods of lockdown, may help ease the pressure on a fire department's possible shortage of staff during the pandemic in case the staff are exposed to or impacted by the virus. Notwithstanding this observation, we very strongly believe that local government officials should not start feeling comfortable with the possibility of fire and rescue service staffing shortages arising and being allowed to persist during the COVID19 or some similar future pandemic in which emergency incidents may temporarily decline in frequency. In particular, as the community recovers and conditions normalize following a pandemic, fire and rescue service managers may encounter huge challenges in re-staffing in the face of normal emergency incident frequencies.

This study may also help fire departments to better understand their situations at different phases of the pandemic, with corresponding public health measures implemented, and their impacts on the demand for their services.

\section{Acknowledgment}

(Left blank during the review process.) 


\section{References}

Asgary, A., Ghaffari, A. and Levy, J. (2010), "Spatial and temporal analyses of structural fire incidents and their causes: a case of Toronto, Canada", Fire Safety Journal, Vol. 45 No. 1, pp. 44-57.

Asgary, A., Rezvani, H., Nosedal-Sánchez, J. and Primiani, J. (2018), "Fires and disasters: examining fire incidents during major disasters and emergencies in Canada", Project report submitted to the Canadian Association of Fire Chiefs, 1 March 2018 (downloadable at https://www.ufv.ca/media/assets/criminology/York-University---Examining-FireIncidents-During-Major-Disasters-in-Canada.pdf).

Boldt, M. and Borg, A. (2016), "Evaluating temporal analysis methods using residential burglary data”, ISPRS International Journal of Geo-Information, Vol. 5 No. 9 (148), pp. 1-22. https://doi.org/10.3390/ijgi5090148.

Bringula, R. and Balahadia, F. (2019), “A spatiotemporal analysis of fire incidents in Manila from 2011-2016: implications for fire prevention”, Disaster Prevention and Management, Vol.28 No. 2, pp. 201-215.

Ceyhan, E., Ertuğay, K. and Düzgün, Ş. (2013), “Exploratory and inferential methods for spatiotemporal analysis of residential fire clustering in urban areas”, Fire Safety Journal, Vol. 58, pp. 226-239.

Chhetri, P., Corcoran, J., Ahmad, S. and Kiran, K.C. (2018), "Examining spatio-temporal patterns, drivers and trends of residential fires in South East Queensland, Australia”, Disaster Prevention and Management, Vol.27 No. 5, pp. 586-603. 
City of Vaughan (2021a), About Vaughan. Available at https://www.vaughan.ca/news/about_vaughan/Pages/default.aspx (accessed February 2, 2021).

City of Vaughan (2021b), City of Vaughan Official Plan 2010 - Volume 1. Available at https://www.vaughan.ca/projects/policy planning_projects/Pages/Vaughan-Official-Plan--Volume-1-and-2.aspx (accessed February 2, 2021).

Cusimano, M., Marshall, S., Rinner, C., Jiang, D. and Chipman, M. (2010), "Patterns of urban violent injury: a spatio-temporal analysis (patterns of violent injury)", PLoS ONE, Vol. 5 No. 1 (e8669), pp. 1-9.

Elia, M., Giannico, V., Lafortezza, R. and Sanesi, G. (2019), "Modeling fire ignition patterns in Mediterranean urban interfaces", Stochastic Environmental Research and Risk Assessment, Vol.33 No. 1, pp. 169-181.

Global News (2020a), “Coronavirus: here's a timeline of COVID-19 cases in Canada”, 3 March 2020, https://globalnews.ca/news/6627505/coronavirus-covid-canada-timeline/.

Global News (2020b), “York Region to enter lockdown zone in Ontario’s COVID-19 pandemic plan”, 11 December 2020, https://globalnews.ca/news/7515895/york-region-lockdowngrey-zone-ontario-coronavirus/.

Guldåker, N. and Hallin, P.-O. (2014), "Spatio-temporal patterns of intentional fires, social stress and socio-economic determinants: a case study of Malmo, Sweden”, Fire Safety Journal, Vol. 70, pp. 71-80.

Liu, C., Qian, J., Guo, D. and Liu, Y. (2018), “A Spatio-temporal scenario model for emergency decision," GeoInformatica, Vol.22 No. 2, pp. 411-433. 
Low, D.E. (2004), "SARS: lessons from Toronto", in Knobler, S., Mahmoud, A., Lemon, S., Mack, A., Sivitz, L. and Oberholtzer, K. (Eds.), Learning from SARS: Preparing for the Next Disease Outbreak: Workshop Summary, The National Academies Press, Washington, DC, pp. 63-71.

Low, G.K.K., Papapreponis, P., Isa, R.M., Gan, S.C., Chee, H.Y., Te, K.K. and Hatta, N.M. (2018), "Geographical distribution and spatio-temporal patterns of hospitalization due to dengue infection at a leading specialist hospital in Malaysia”, Geospatial Health, Vol. 13 No. 642, pp. 127-134.

Marco, M., López-Quílez, A., Conesa, D., Gracia, E. and Lila, M. (2017), “Spatio-temporal analysis of suicide-related emergency calls", International Journal of Environmental Research and Public Health, Vol.14 No. 7 (735), pp. 1-13.

Office of the Fire Marshal of Ontario (2009), Standard Incident Report Codes List, issued January 2009.

Office of the Fire Marshal of Ontario (2013), Standard Incident and Injury Reporting Manual, created January 2009; last modified May 2013.

Ontario Ministry of Health (2021), "Diseases: Severe Acute Respiratory Syndrome (SARS)". Available at https://www.health.gov.on.ca/en/public/publications/pub sars.aspx.

Province of Ontario (2020a), "Ontario enacts declaration of emergency to protect the public", news release, 17 March 2020. Available at https://news.ontario.ca/en/release/56356/ontarioenacts-declaration-of-emergency-to-protect-the-public.

Province of Ontario (2020b), "Reopening of Ontario in stages", Archived. Available at https://www.ontario.ca/page/reopening-ontario-stages. 
Province of Ontario (2020c), “A framework for reopening our province: Stage 3”. Downloadable at https://files.ontario.ca/mof-framework-reopening-province-stage-3-en-2020-07-13v2.pdf.

Province of Ontario (2020d), "Ontario moving additional region to Modified Stage 2", news release, 16 October 2020. Available at https://news.ontario.ca/en/release/58842/ontariomoving-additional-region-to-modified-stage-2.

Province of Ontario (2020e), “COVID-19 Response Framework: Keeping Ontario Safe and Open —Lockdown Measures”, 22 November 2020. Downloadable at https://files.ontario.ca/mohcovid-19-response-framework-keeping-ontario-safe-and-open-en-2020-11-24.pdf.

Province of Ontario (2021), "Ontario declares second provincial emergency to address COVID19 crisis and save lives", news release, 12 January 2021, https://news.ontario.ca/en/release/59922/ontario-declares-second-provincial-emergency-toaddress-covid-19-crisis-and-save-lives.

Public Health Agency of Canada (2004), Chapter 2: learning from SARS: renewal of public health in Canada - SARS in Canada: anatomy of an outbreak (Report of the National Advisory Committee on SARS and Public Health; archived; last updated 08 November 2004). Available at https://www.canada.ca/en/public-health/services/reports-publications/learningsars-renewal-public-health-canada/chapter-2-sars-canada-anatomy-outbreak.html.

Public Health Ontario (2021). "COVID-19 in Ontario: January 15, 2020 to January 14, 2021". Downloadable at https://files.ontario.ca/moh-covid-19-report-en-2021-01-15_v2.pdf.

Reuters (2020), "Canada identifies first case of coronavirus", 25 January 2020, https://www.reuters.com/article/us-china-health-canada-idUSKBN1ZO0T9. 
Santos, R.B. (2017), Crime Analysis with Crime Mapping, 4th ed., Sage Publications, Thousand Oaks, CA.

Shafiei Sabet, M., Asgary, A. and Solis, A.O. (2019), "Emergency calls during the 2013 Southern Ontario Ice Storm: case study of Vaughan”, International Journal of Emergency Services, Vol. 8 No. 3, pp. 292-314.

Solis, A.O., Nosedal-Sánchez, J., Asgary, A., Rizzi, D., Plested, K., Longo, F., Briga, A., Castagna, A. and Zaccaro, B. (2019), “Agent-based simulation of a fire department's response to emergency incidents: an updated model", Proceedings of the 9th International Defence and Homeland Security Simulation Workshop, Lisbon, Portugal, September 2019, pp. 39-46.

Špatenková, O. and Virrantaus, K. (2013), "Discovering spatio-temporal relationships in the distribution of building fires", Fire Safety Journal, Vol. 62 Part A, pp. 49-63.

Tang, J-H., Tseng, T-J. and Chan, T-C. (2019), “Detecting spatio-temporal hotspots of scarlet fever in Taiwan with spatio-temporal Gi* statistic", PLoS ONE, Vol. 1 No. 4, (e0215434), 1-14.

Vasiliev, I.R. (1997), “Mapping time”, Cartographica: The International Journal for Geographic Information and Geovisualization, Vol. 34 No. 2, pp. 1-51.

Wikipedia (2021), List of municipalities in the Greater Toronto Area. Available at https://en.wikipedia.org/wiki/List_of_municipalities_in the Greater_Toronto_Area.

Wuschke, K., Clare, J. and Garis, L. (2013), “Temporal and geographic clustering of residential structure fires: a theoretical platform for targeted fire prevention", Fire Safety Journal, Vol. 62 Part A, pp. 3-12.

Xia, T., Song, X., Zhang, H., Song, X., Kanasugi, H. and Shibasaki, R. (2019), "Measuring spatiotemporal accessibility to emergency medical services through big GPS data", Health and Place, Vol.56, pp. 53-62. 
Yoo, E-H., Brown, P. and Eum, Y. (2018), “Ambient air quality and spatio-temporal patterns of cardiovascular emergency department visits", International Journal of Health Geographics, Vol.17 No. 1, pp. 1-16.

York Region (2020), "York Region placed in lockdown for minimum 28 days", media release, 11 $\begin{array}{lll}\text { December } & 2020 . & \text { Available }\end{array}$ https://www.york.ca/wps/portal/yorkhome/newsroom/mediarelease/yorkregionplacedinloc kdown/.

York Region (2021), "York Region Paramedic Services". Available at https://www.york.ca/wps/portal/yorkhome/health/yr/paramedicservices/.

\section{Appendix}

Table A about here 


\section{Shifting patterns of emergency incidents during the COVID-19 pandemic in the City of Vaughan, Canada}

\section{FIGURES}
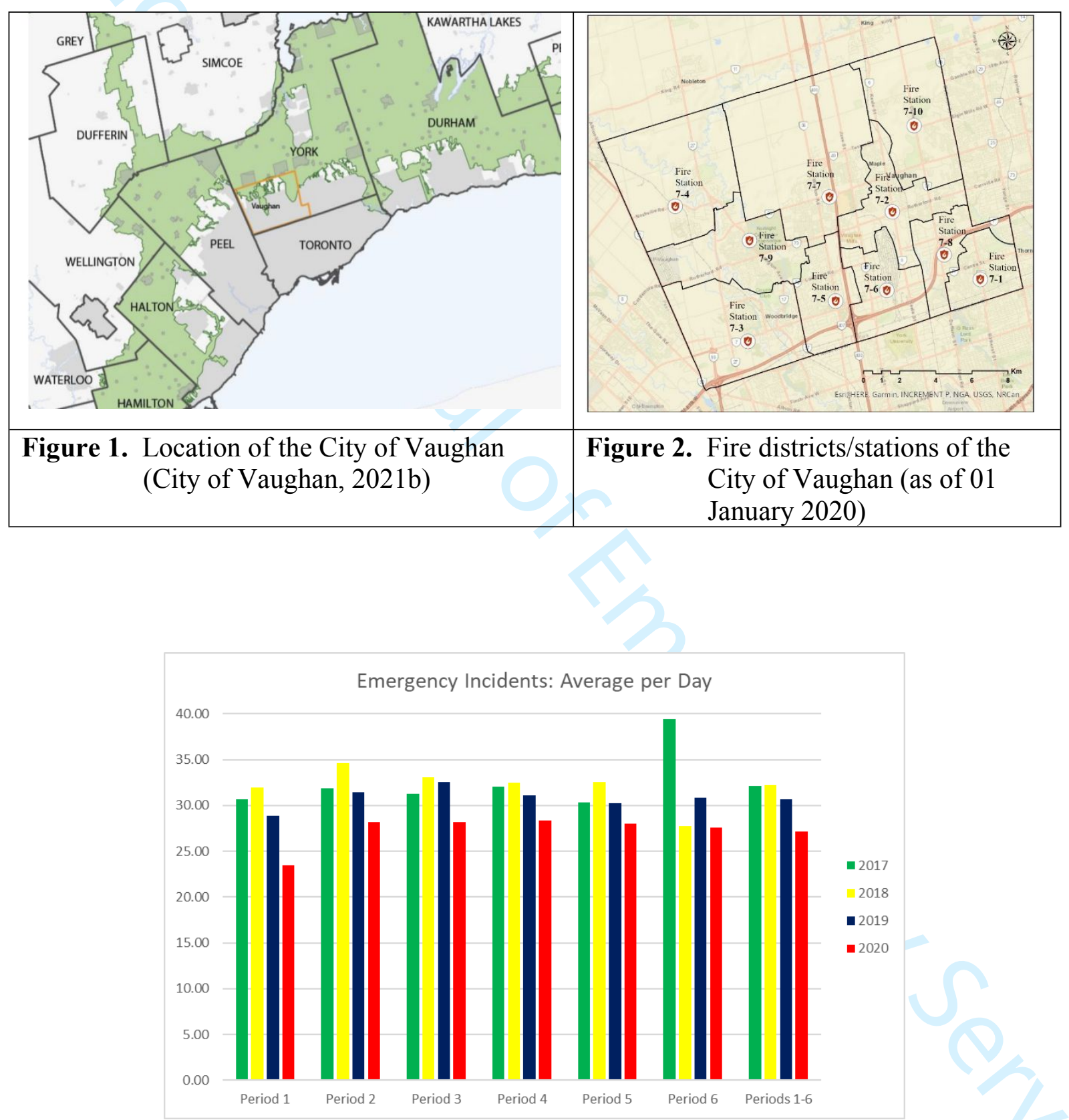

Figure 3. Emergency incidents: Average per day 


\begin{tabular}{|c|c|c|c|}
\hline Daily Frequencies of Emergency Incidents: \\
Period 1 (2020 vs. 2019)
\end{tabular}

Note: The red dots in Figures 4(a) through 4(f) show the numbers of emergency incidents on a day-to-day basis during Periods 1 through 6, respectively, while the blue dots show the corresponding daily numbers during the same period in the previous year.

Figure 4. Daily frequencies of emergency incidents 


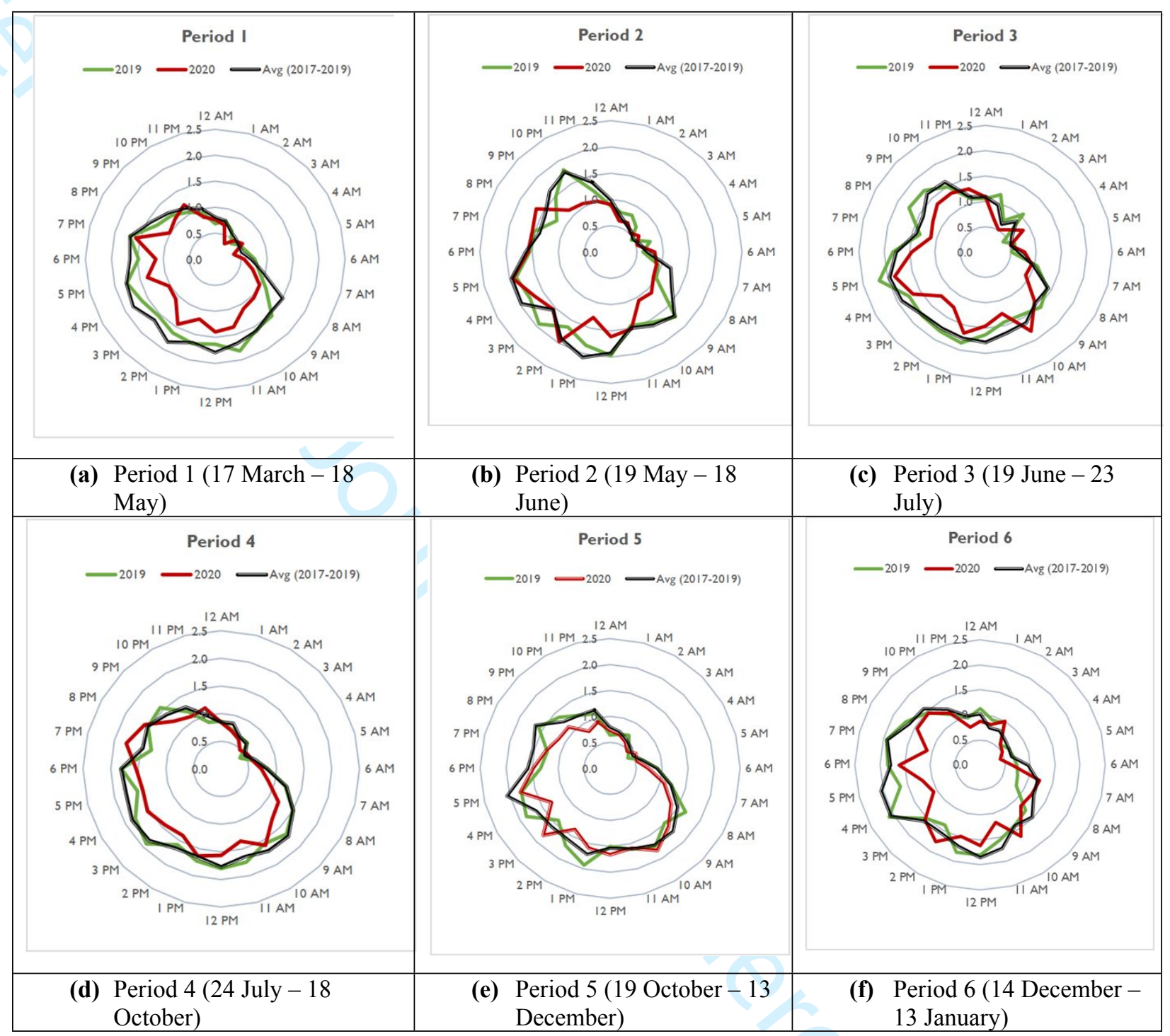

Figure 5. Distributions of all emergency incidents according to hours of occurrence (daily average in each hour) 


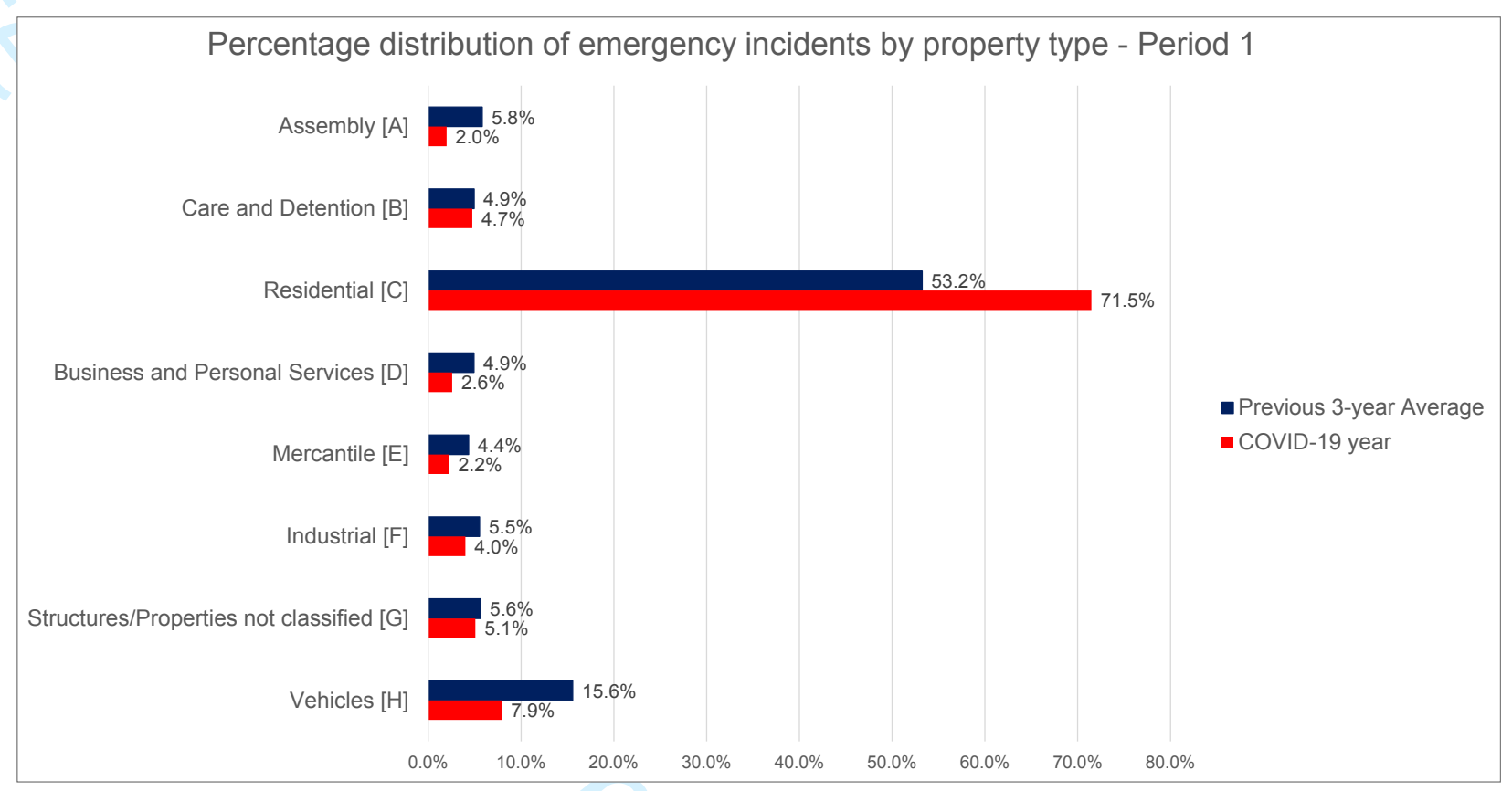

Figure 6(a). Distribution of emergency incidents by property type - Period 1

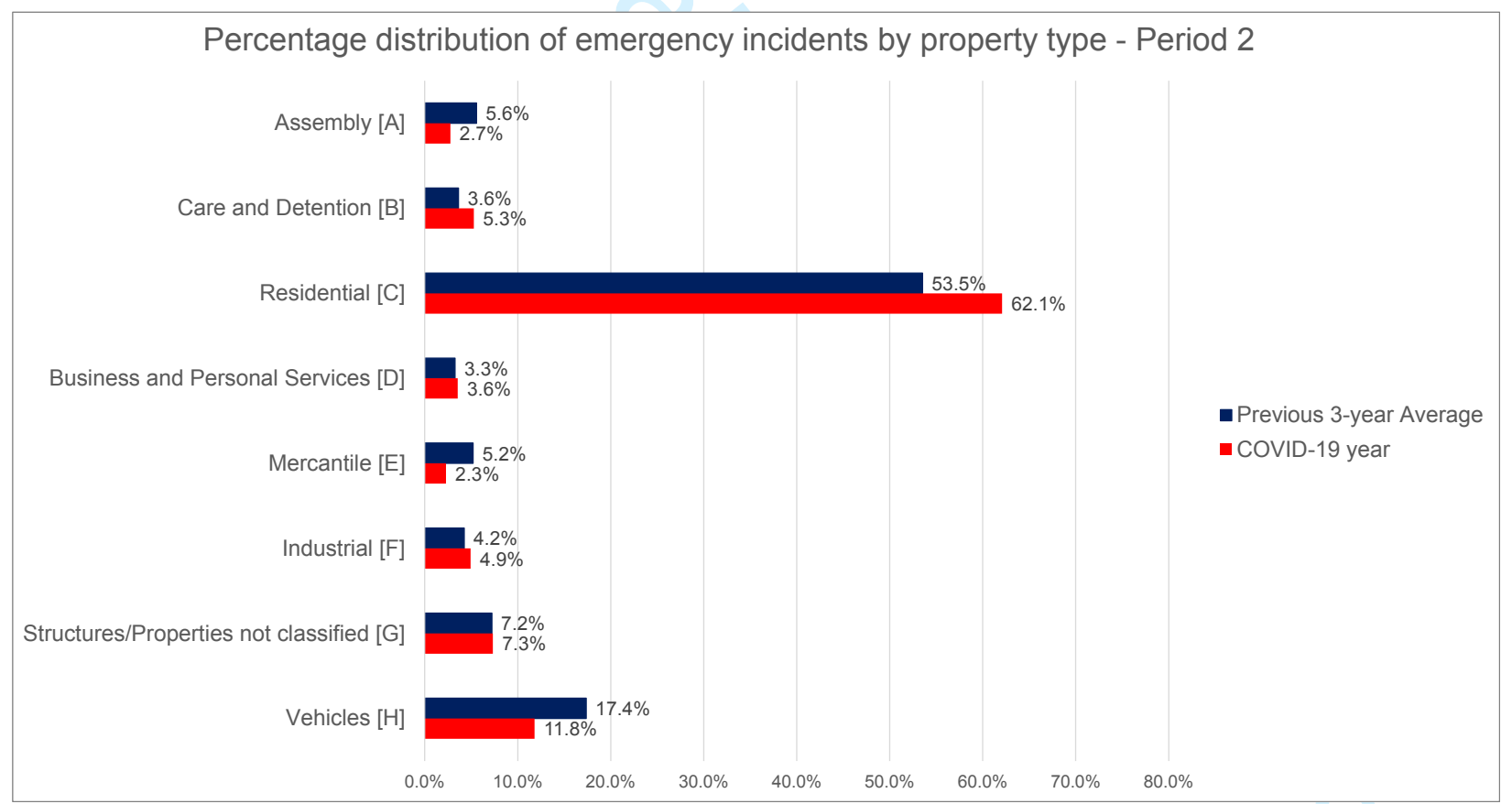

Figure 6(b). Distribution of emergency incidents by property type - Period 2 


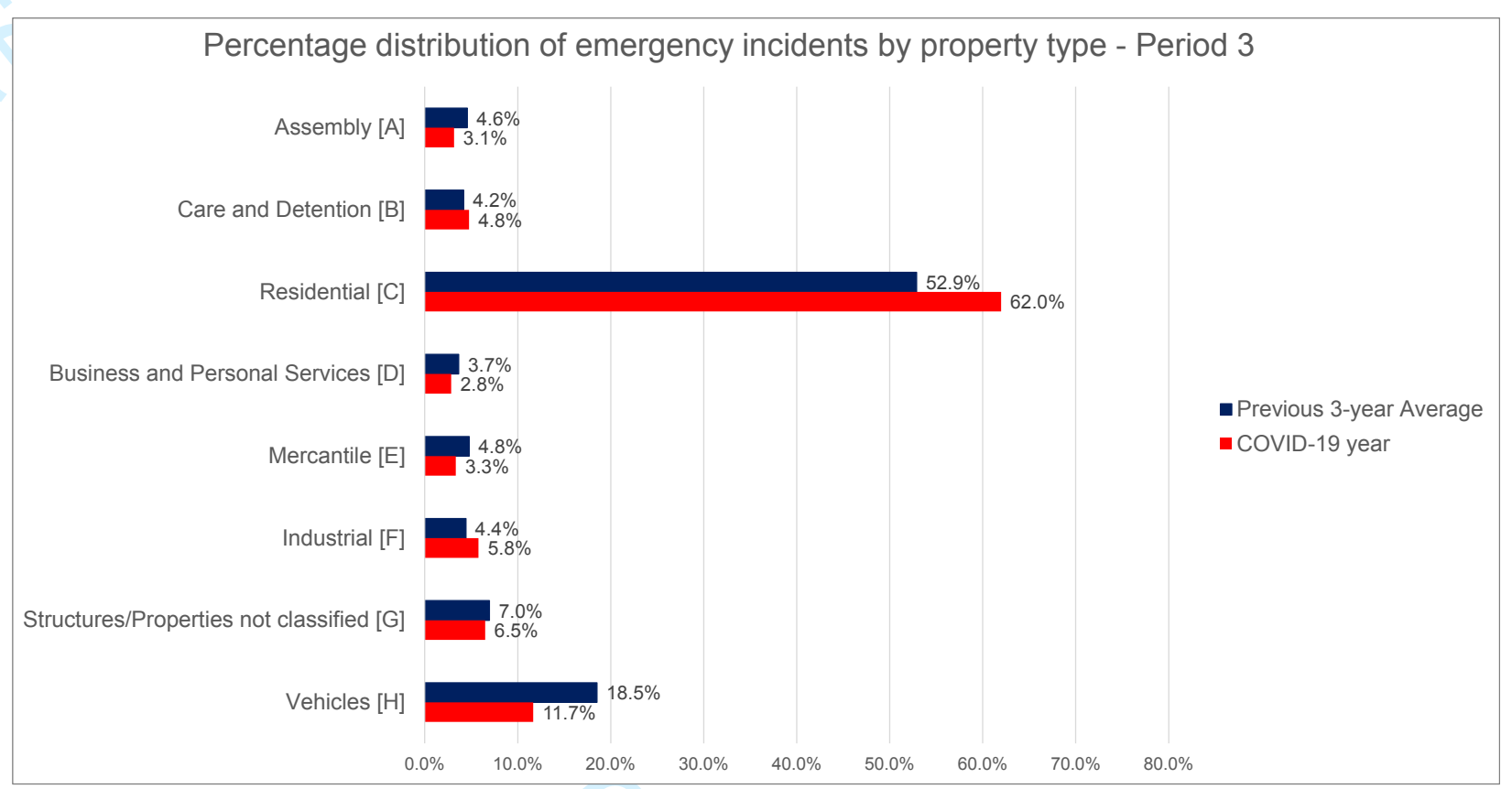

Figure 6(c). Distribution of emergency incidents by property type - Period 3

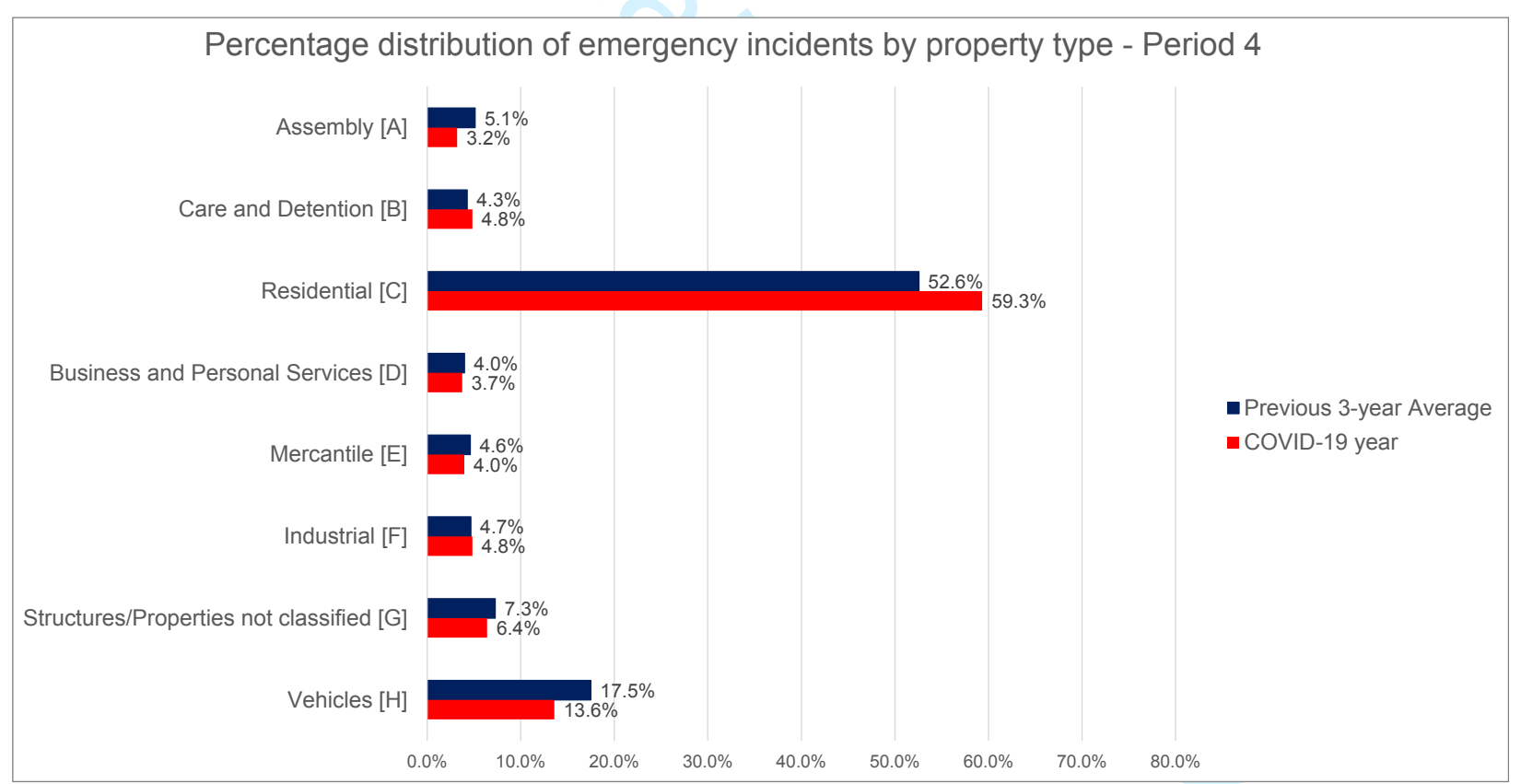

Figure 6(d). Distribution of emergency incidents by property type - Period 4 


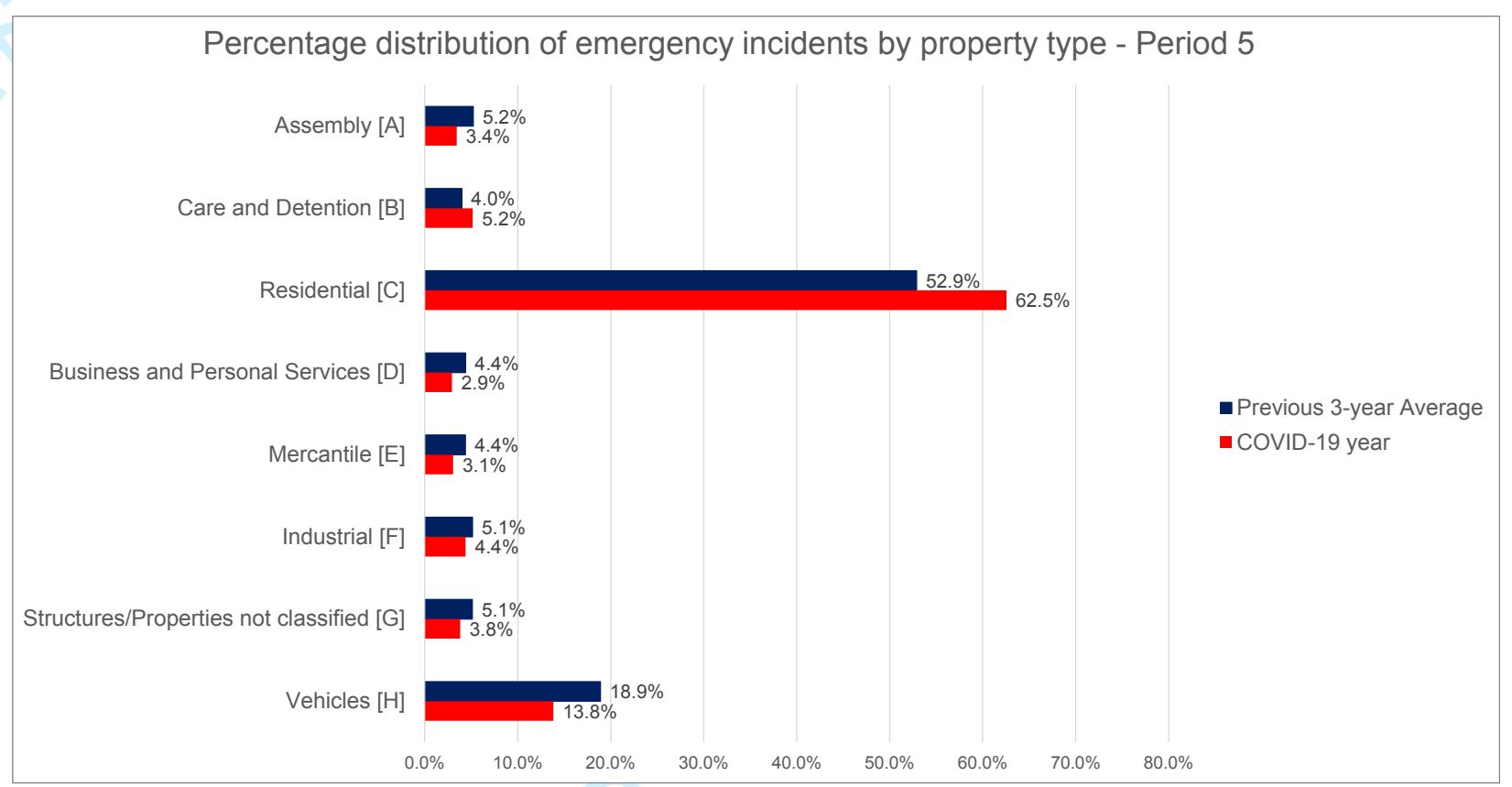

Figure 6(e). Distribution of emergency incidents by property type - Period 5

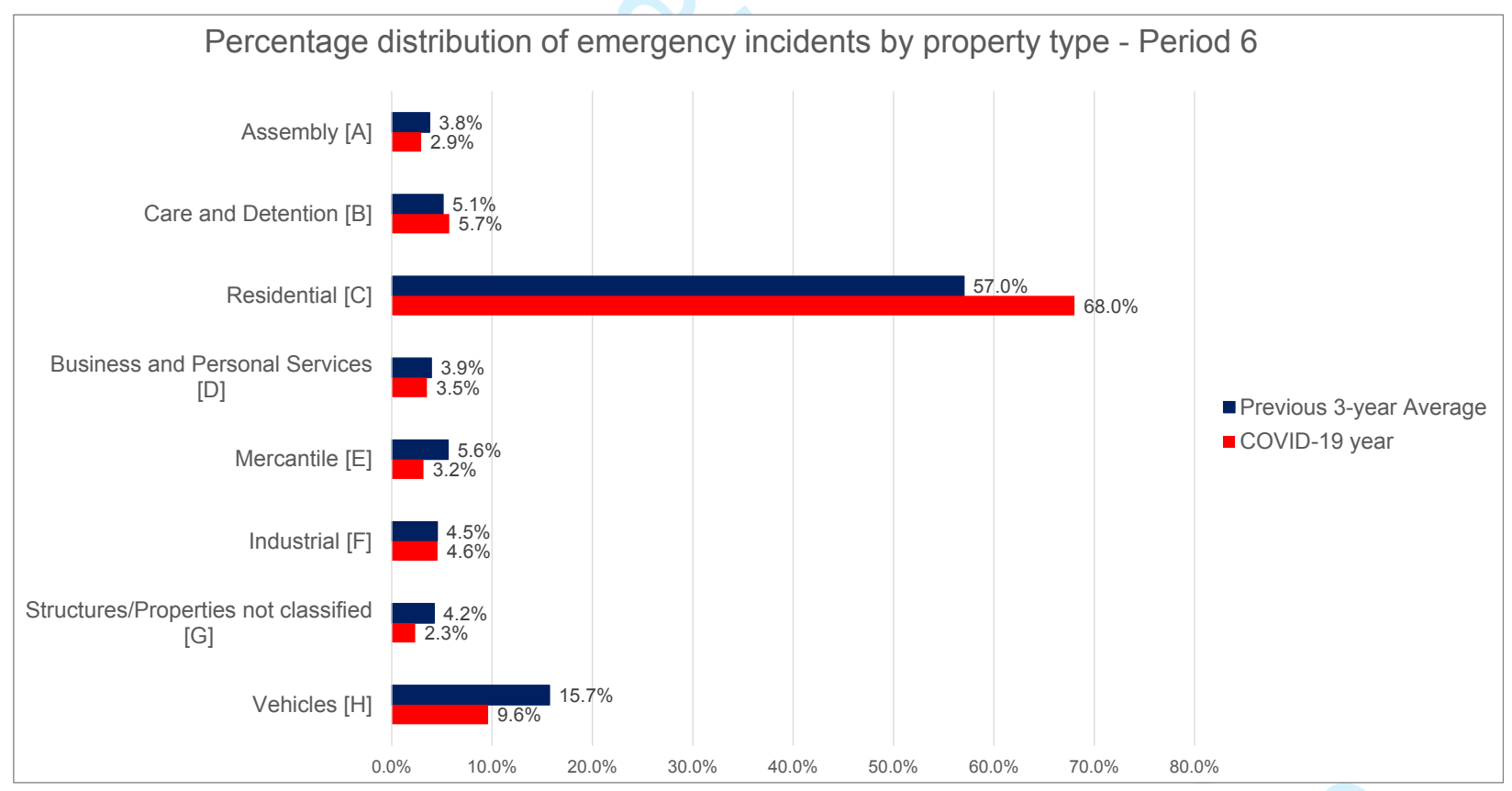

Figure 6(f). Distribution of emergency incidents by property type - Period 6 


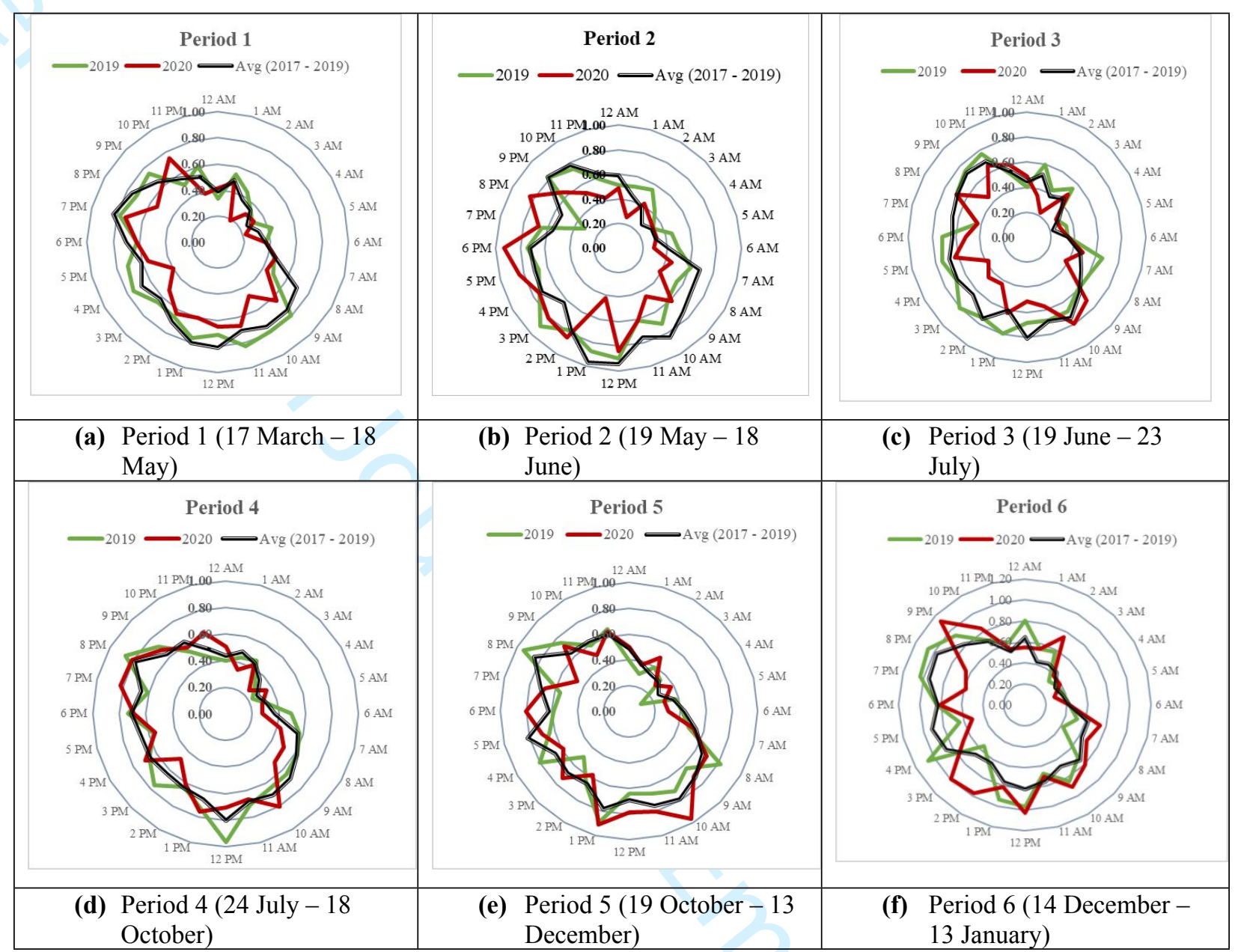

Figure 7. Distributions of medical emergencies according to hours of occurrence (daily average in each hour) 


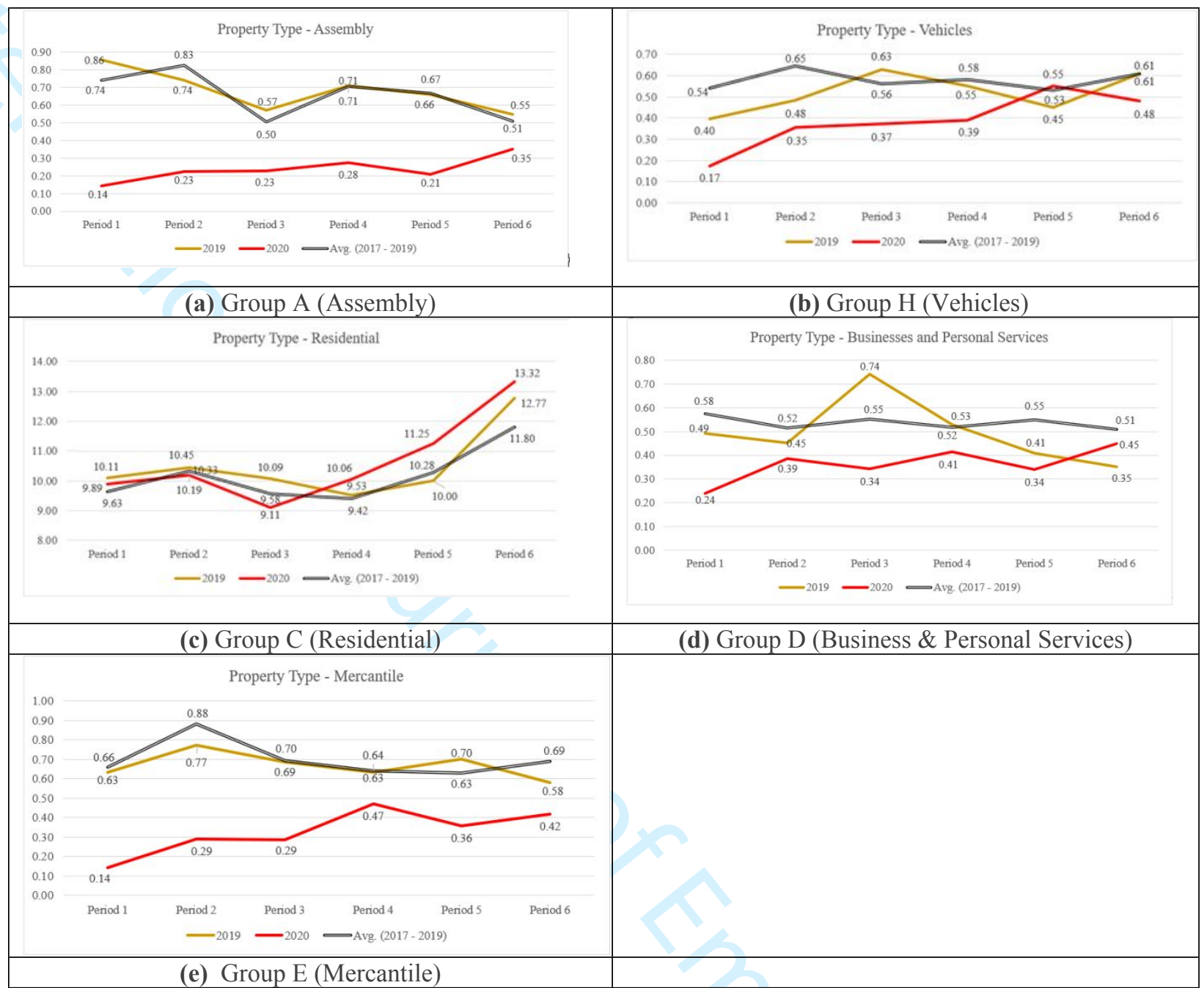

Figure 8. Daily average numbers of medical emergency responses by property type 


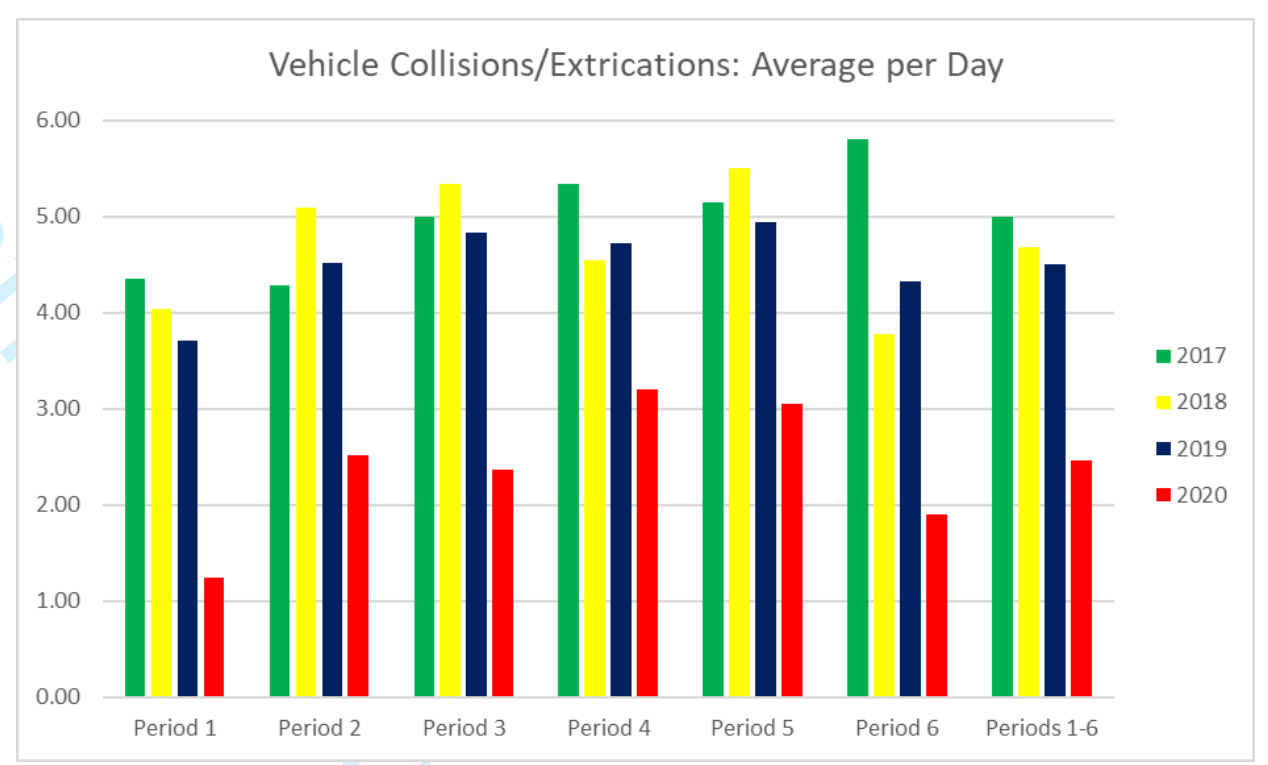

Figure 9. Vehicle collisions/extrications: Average per day 


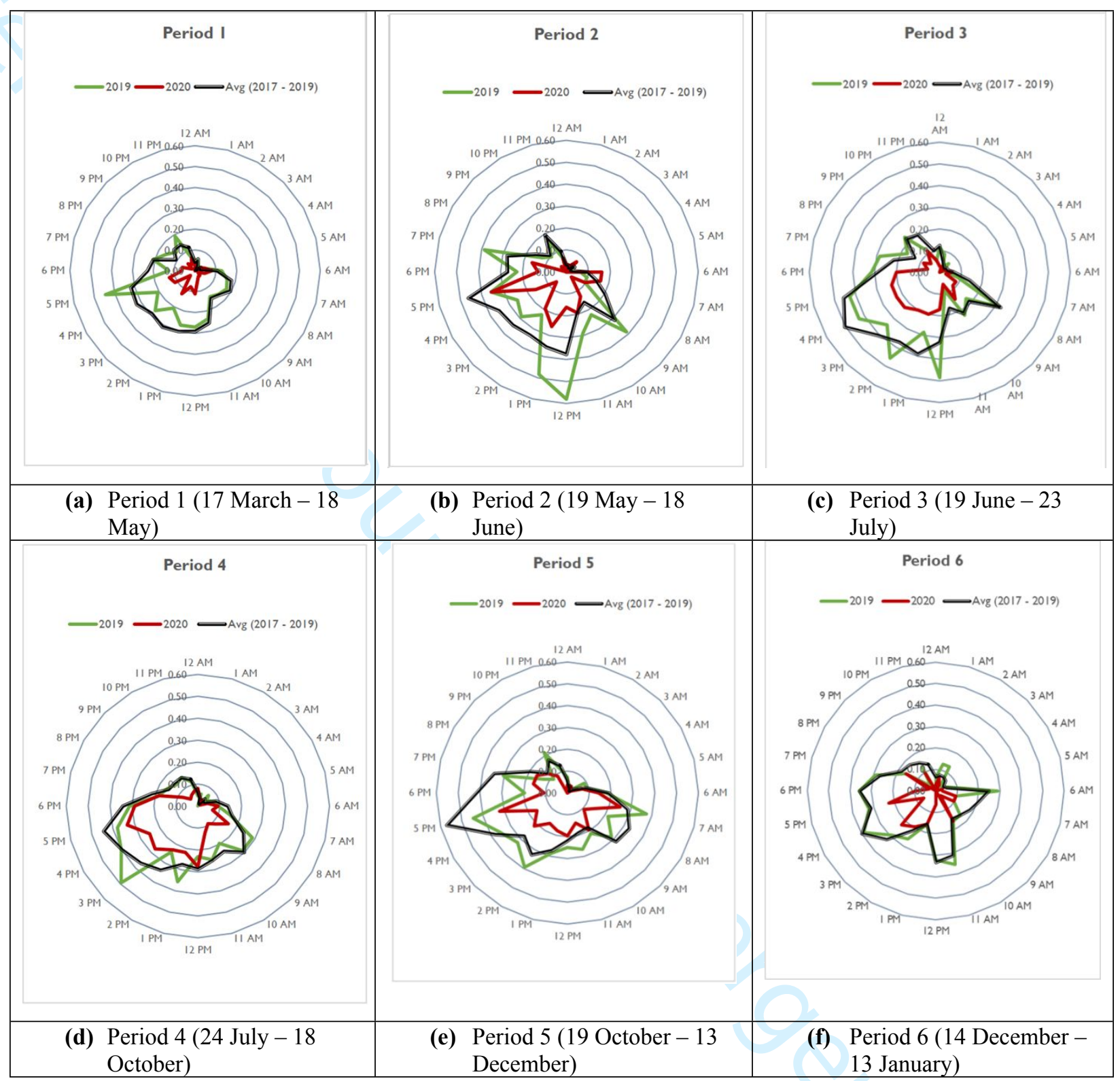

Figure 10. Distributions of vehicle collisions/extrications according to hours of occurrence (daily average in each hour) 


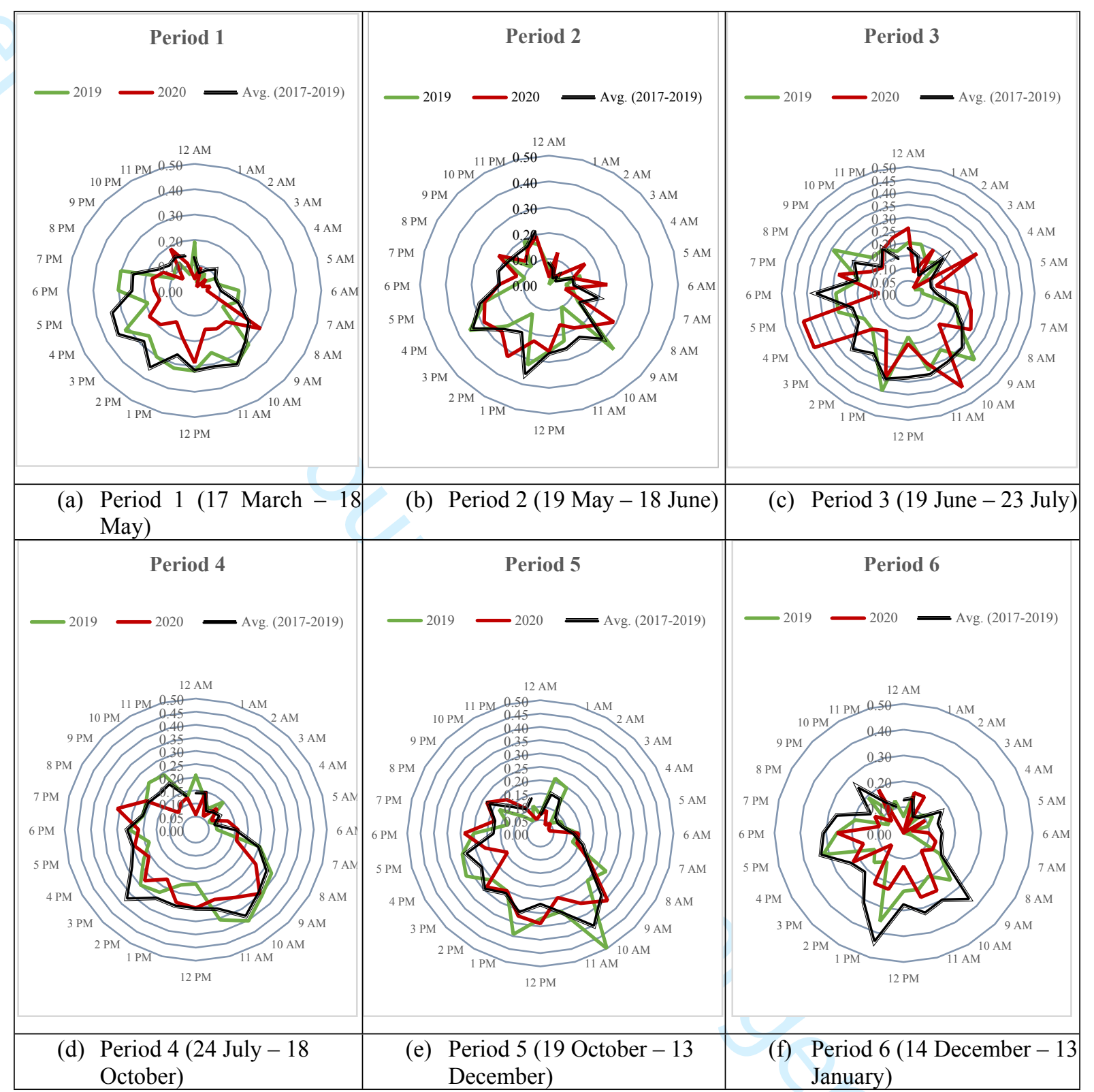

Figure 11. Distributions of false fire calls according to hours of occurrence

(daily average in each hour) 


\section{Average Response Time}

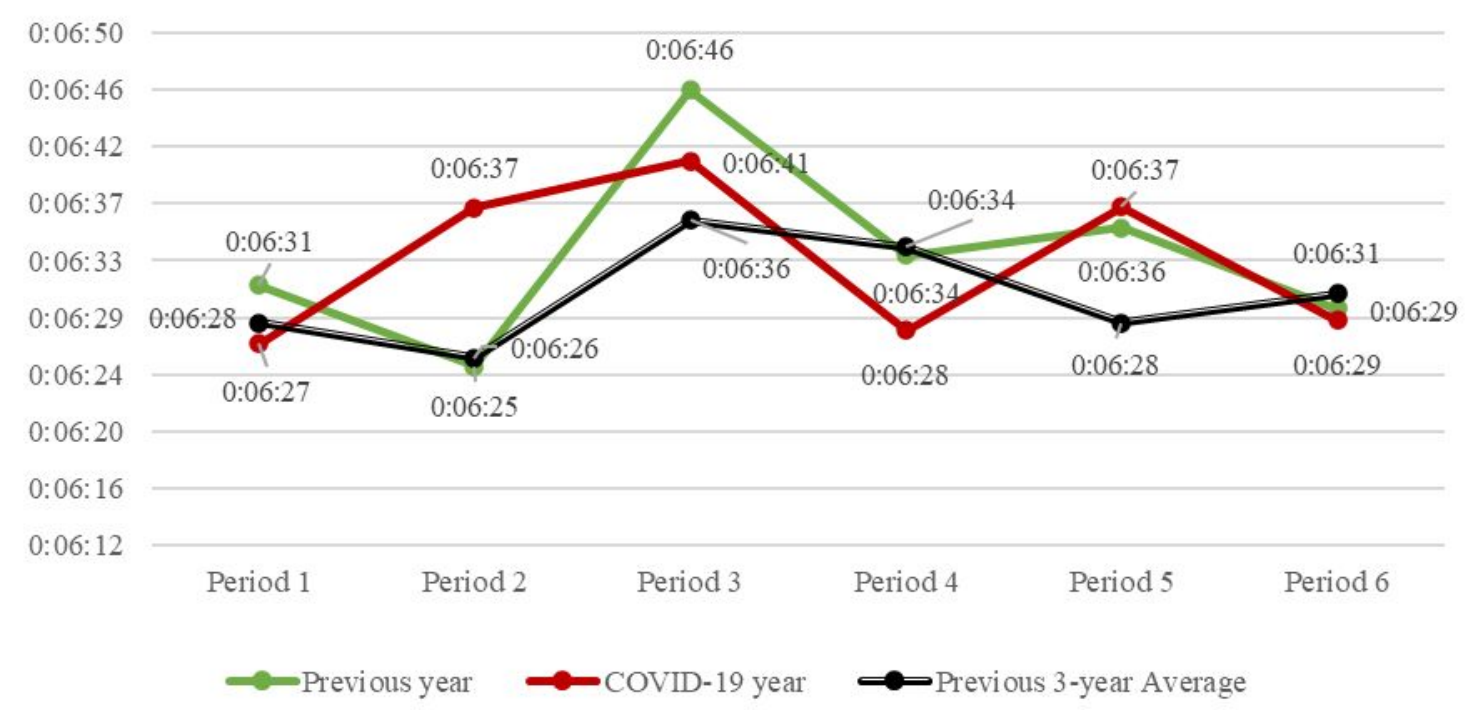

Figure 12. Average response times

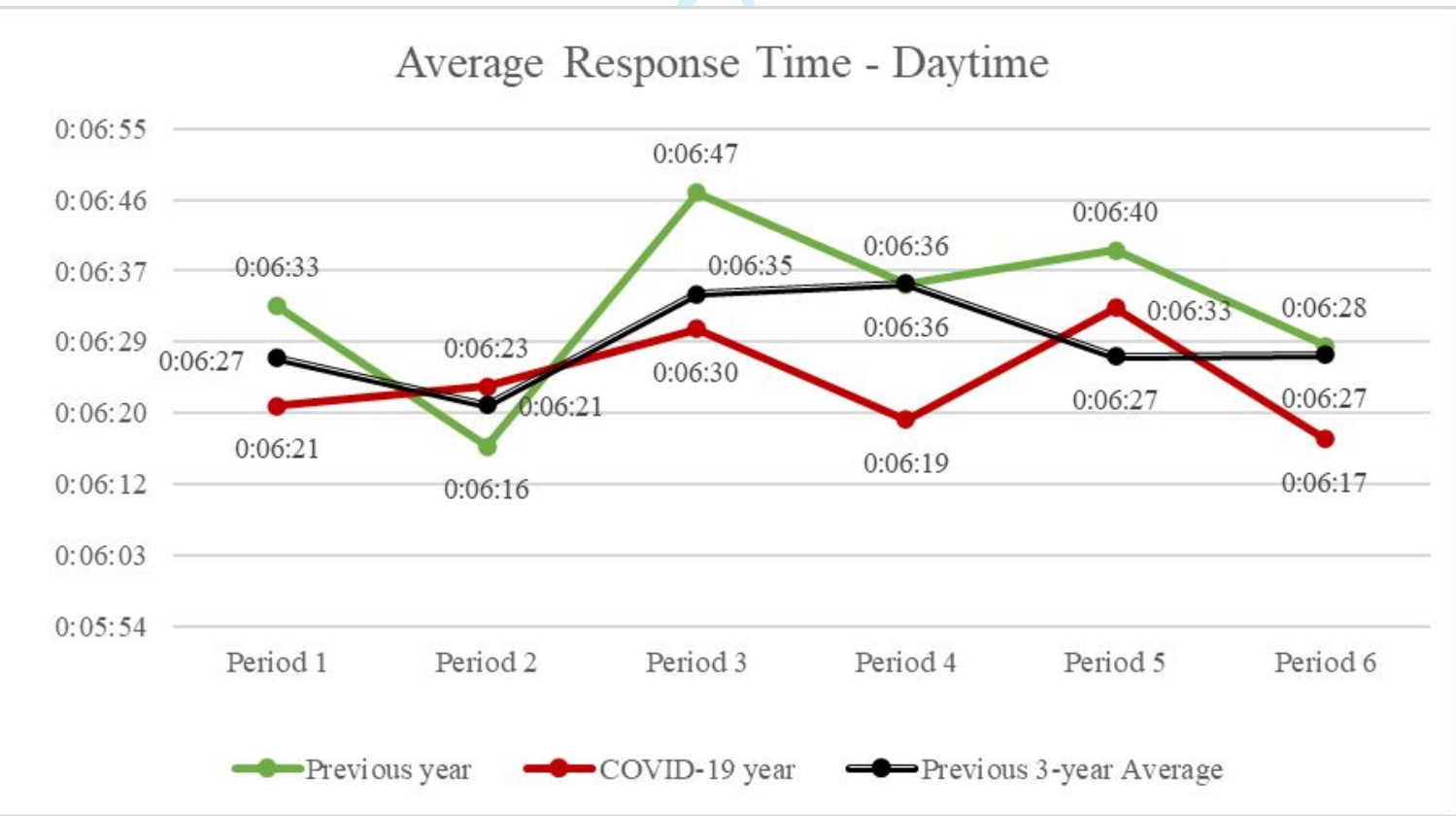

Figure 13. Average response times during daytime hours (between 6:00:00 a.m. and 5:59:59 p.m.) 


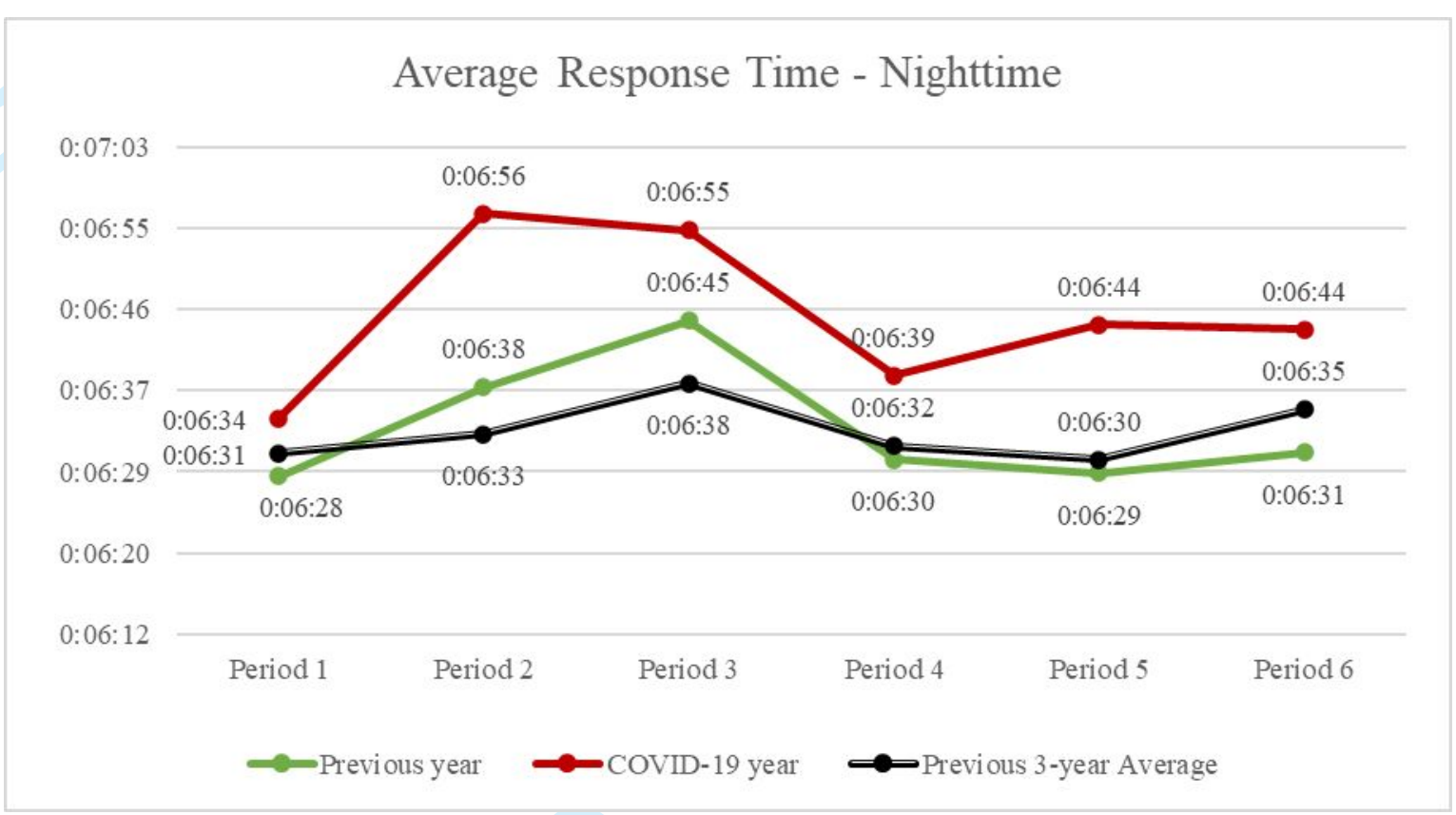

Figure 14. Average response times during nighttime hours (between 6:00:00 p.m. and 5:59:59 a.m.)

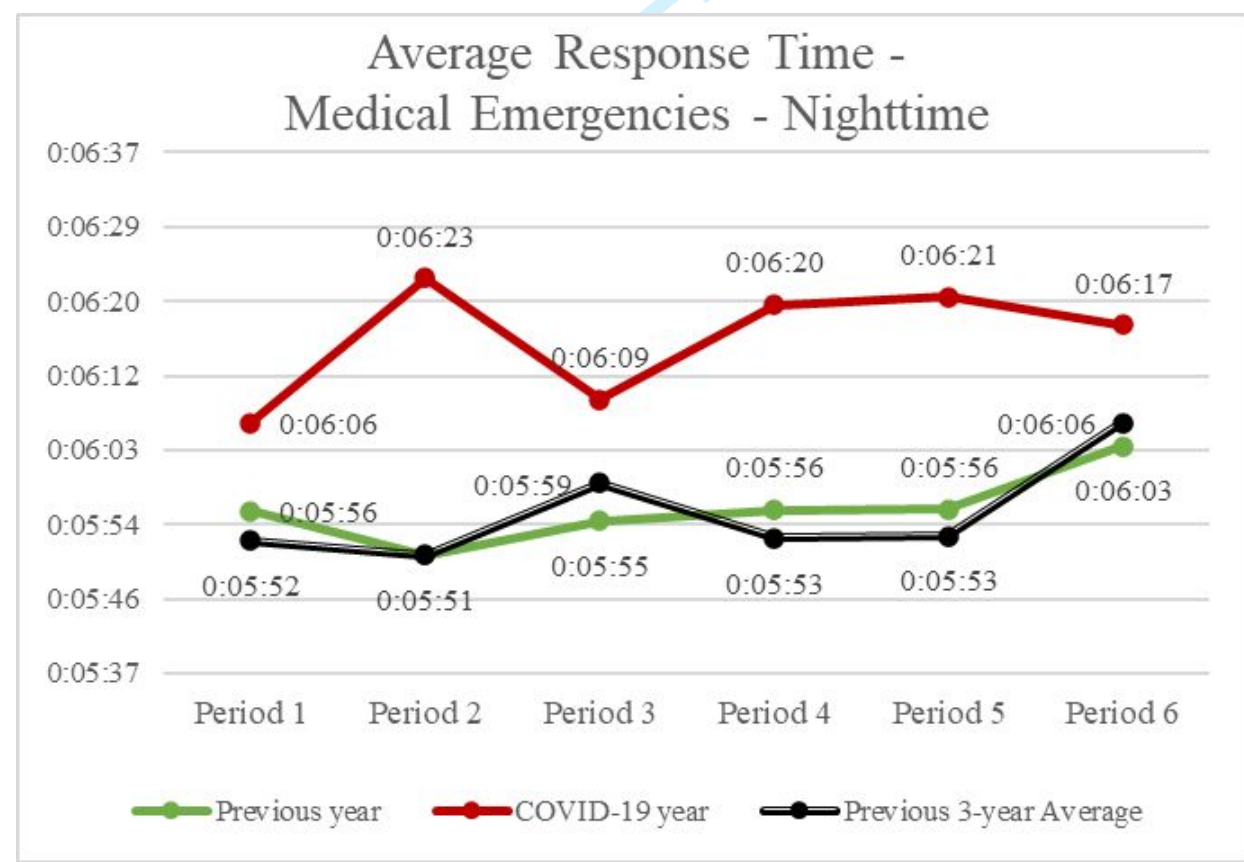

Figure 15. Average response times for medical emergencies during nighttime hours (between 6:00:00 p.m. and 5:59:59 a.m.) 


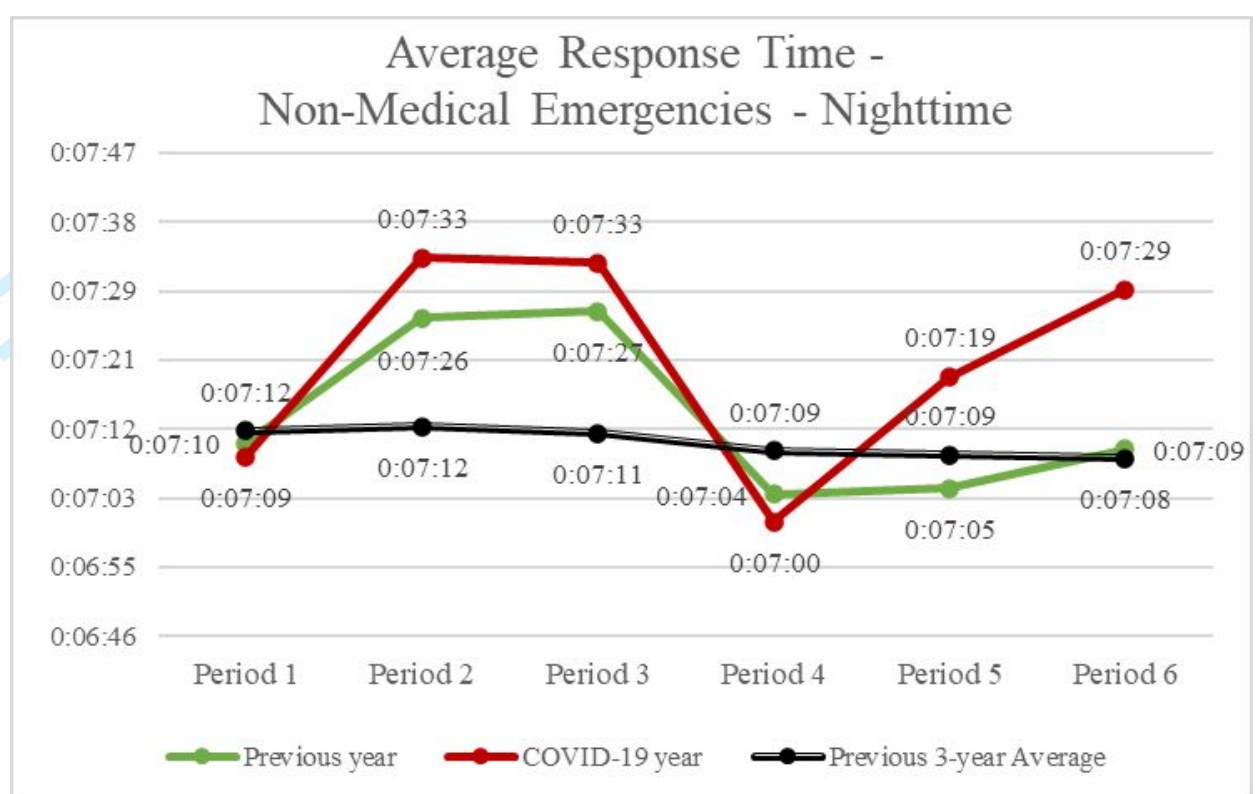

Figure 16. Average response times for non-medical emergencies during nighttime hours (between 6:00:00 p.m. and 5:59:59 a.m.)

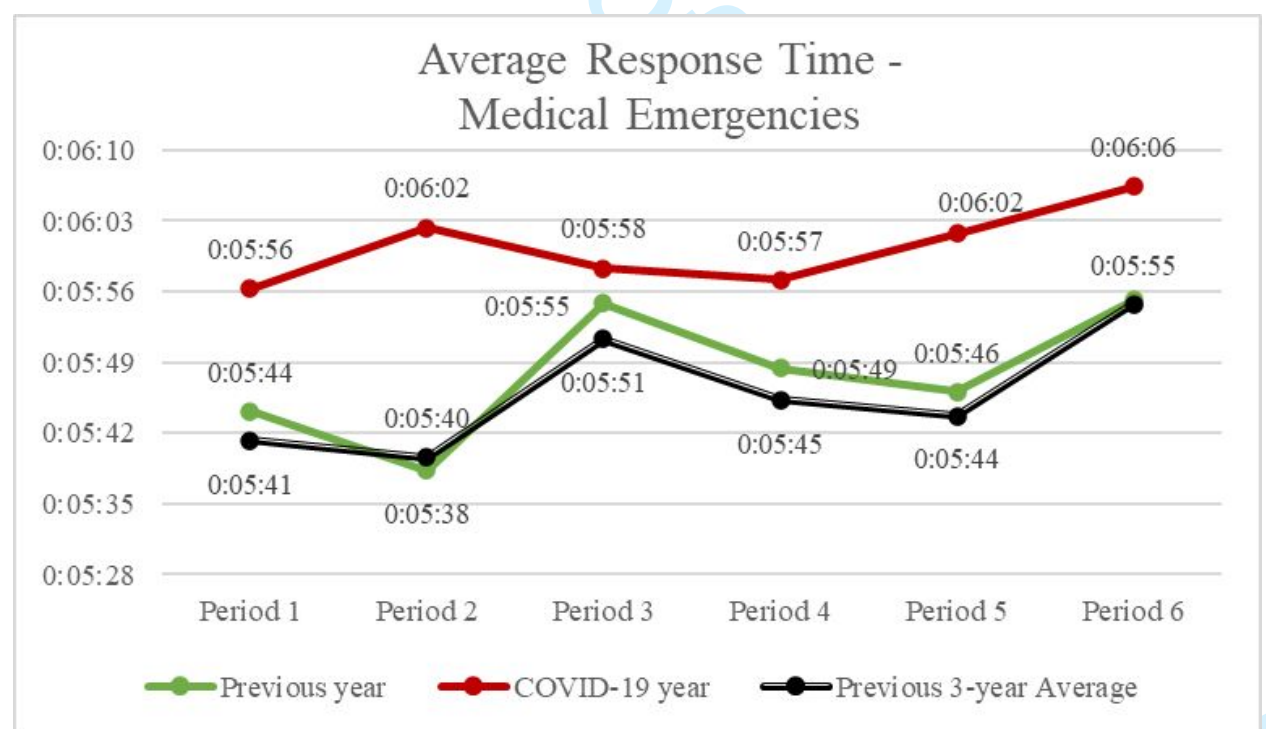

Figure 17. Average response times for medical emergencies on 24-hour basis 


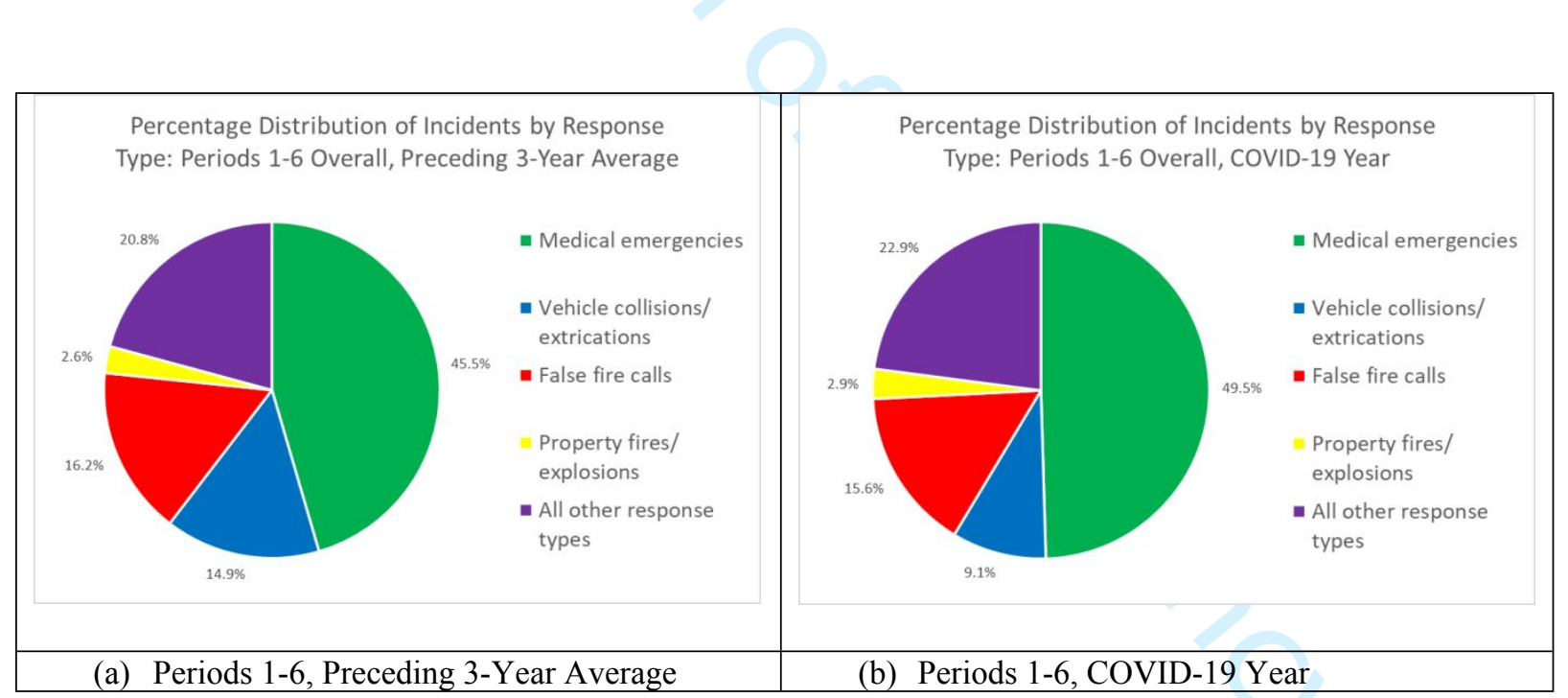

Figure 19. Distribution of Incidents by Response Type: Pre-Pandemic vs. Pandemic

\section{Percentage Change vs Preceding 3-Year Average}

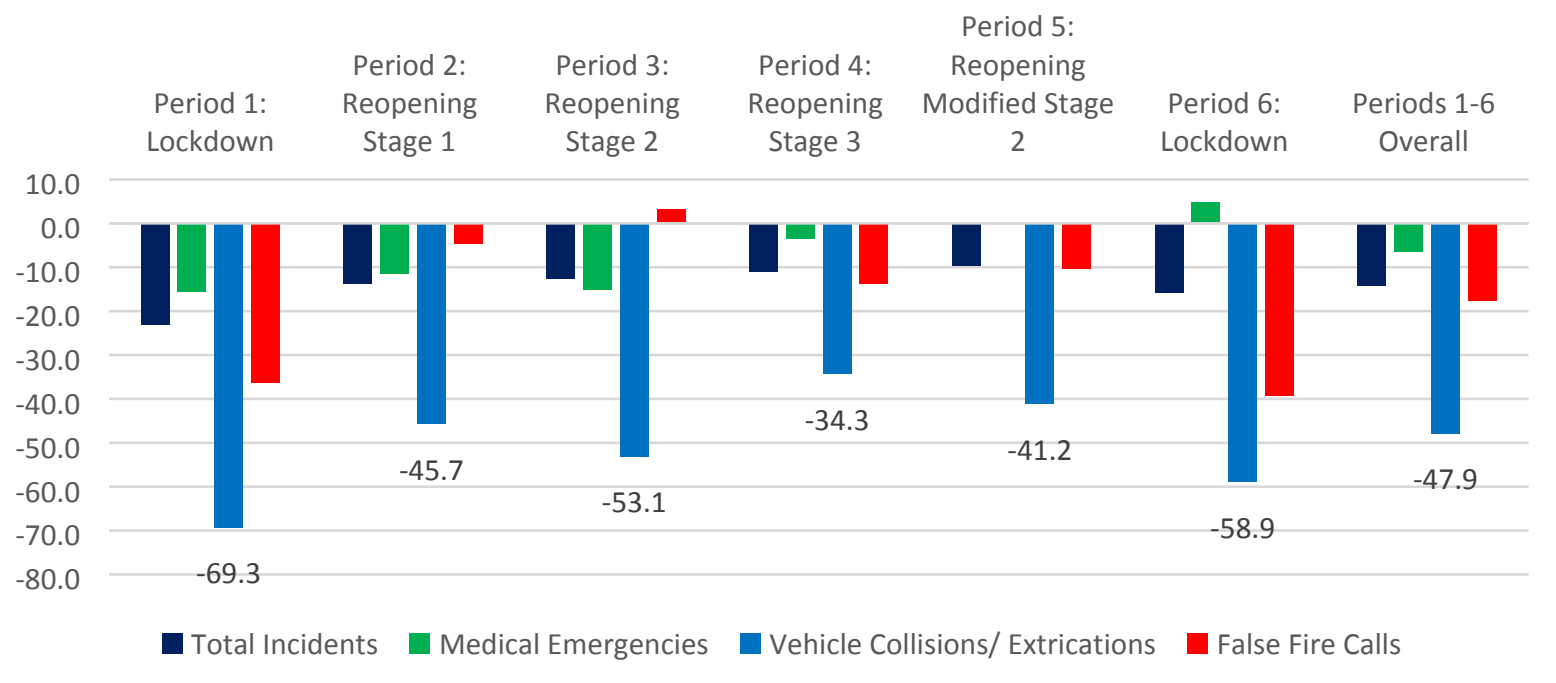

Figure 18. Percentage changes in emergency incidents: total and by type 


\title{
Shifting patterns of emergency incidents during the COVID-19 pandemic in the City of Vaughan, Canada
}

\author{
TABLES
}

Table I. Aggregate and average daily numbers of VFRS incidents

\begin{tabular}{|c|c|c|c|c|c|c|c|c|c|c|c|}
\hline & \multirow[b]{2}{*}{$\begin{array}{l}\text { \# of } \\
\text { Days }\end{array}$} & \multicolumn{2}{|c|}{$\begin{array}{c}\text { Preceding 3-Year } \\
\text { Average }\end{array}$} & \multicolumn{2}{|c|}{ Previous Year } & \multicolumn{2}{|c|}{ COVID-19 Year } & \multicolumn{2}{|c|}{$\begin{array}{l}\Delta \text { vs. Preceding } \\
\text { 3-Year Average }\end{array}$} & \multicolumn{2}{|c|}{$\begin{array}{c}\Delta \text { vs. Previous } \\
\text { Year }\end{array}$} \\
\hline & & $\begin{array}{c}\text { No. of } \\
\text { Incidents }\end{array}$ & $\begin{array}{l}\text { Average } \\
\text { No./Day } \\
\end{array}$ & $\begin{array}{c}\text { No. of } \\
\text { Incidents }\end{array}$ & $\begin{array}{l}\text { Average } \\
\text { No./Day } \\
\end{array}$ & $\begin{array}{c}\text { No. of } \\
\text { Incidents }\end{array}$ & $\begin{array}{l}\text { Average } \\
\text { No./Day } \\
\end{array}$ & $\begin{array}{c}\text { No. of } \\
\text { Incidents }\end{array}$ & $\%$ & $\begin{array}{c}\text { No. of } \\
\text { Incidents }\end{array}$ & $\%$ \\
\hline Period 1 (17 March - 18 May) & 63 & $1,922.3$ & $\overline{30.5}$ & 1,821 & $\overline{28.9}$ & 1,476 & $\overline{23.4}$ & -446.3 & $-23.2 \%$ & -345 & $-18.9 \%$ \\
\hline Period 2 (19 May - 18 June) & 31 & $1,012.0$ & 32.6 & 974 & 31.4 & 873 & 28.2 & -139.0 & $-13.7 \%$ & -101 & $-10.4 \%$ \\
\hline Period 3 (19 June - 23 July) & 35 & $1,130.0$ & 32.3 & 1,139 & 32.5 & 986 & 28.2 & -144.0 & $-12.7 \%$ & -153 & $-13.4 \%$ \\
\hline Period 4 (24 July - 18 October) & 87 & $2,774.7$ & 31.9 & 2,705 & 31.1 & 2,466 & 28.3 & -308.7 & $-11.1 \%$ & -239 & $-8.8 \%$ \\
\hline Period 5 (19 October - 13 December) & 56 & $1,738.3$ & 31.0 & 1,694 & 30.3 & 1,570 & 28.0 & -168.3 & $-9.7 \%$ & -124 & $-7.3 \%$ \\
\hline Period 6 (14 December - 13 January) & 31 & $1,013.7$ & 32.7 & 957 & 30.9 & 854 & 27.5 & -159.7 & $-15.8 \%$ & -103 & $-10.8 \%$ \\
\hline Total for Periods 1-6 & 303 & $9,591.0$ & 31.7 & 9,290 & 30.7 & 8,225 & 27.1 & $-1,366.0$ & $-14.2 \%$ & $-1,065$ & $-11.5 \%$ \\
\hline
\end{tabular}

Table II. Significance of differences between daily means of emergency incidents

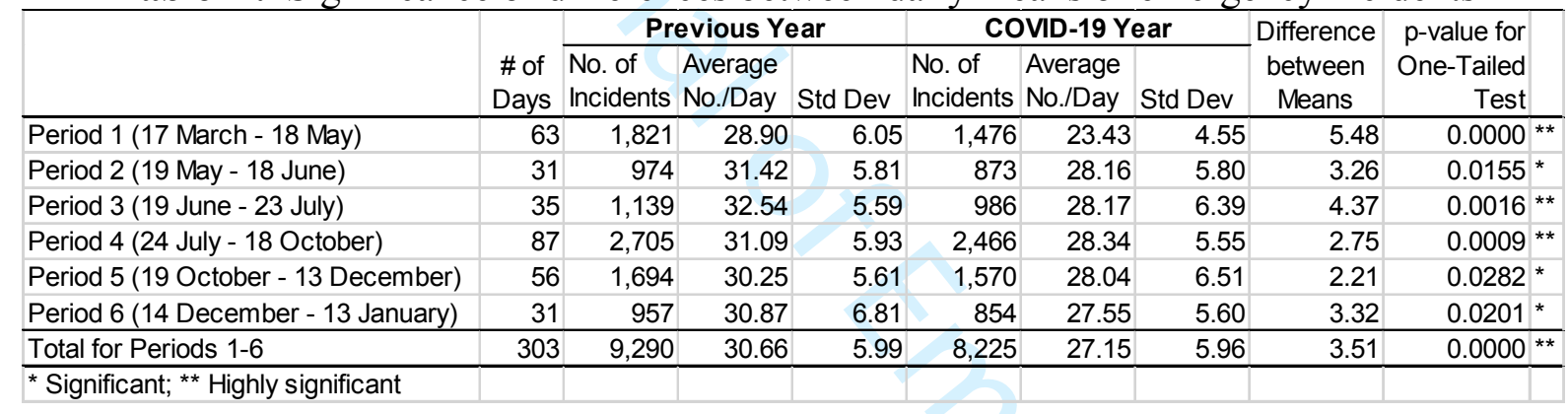

Table III. Number of incidents in Period 1 by property type

\begin{tabular}{|c|c|c|c|c|c|c|c|c|c|}
\hline \multirow[b]{2}{*}{ Property Type } & \multicolumn{3}{|c|}{ Average 2017-2019 } & \multicolumn{3}{|c|}{2019} & \multicolumn{3}{|c|}{2020} \\
\hline & $\begin{array}{c}\text { No. of } \\
\text { Incidents }\end{array}$ & $\%$ & $\begin{array}{c}\text { Avg No. of } \\
\text { Incidents/ } \\
\text { Day }\end{array}$ & $\begin{array}{c}\text { No. of } \\
\text { Incidents }\end{array}$ & $\%$ & $\begin{array}{c}\text { Avg No. of } \\
\text { Incidents/ } \\
\text { Day }\end{array}$ & $\begin{array}{c}\text { No. of } \\
\text { Incidents }\end{array}$ & $\%$ & $\begin{array}{c}\text { Avg No. of } \\
\text { Incidents/ } \\
\text { Day }\end{array}$ \\
\hline Assembly (A) & 111.7 & $5.8 \%$ & 1.8 & 116 & $6.4 \%$ & 1.8 & 29 & $2.0 \%$ & 0.5 \\
\hline Care and Detention (B) & 95.0 & $5.0 \%$ & 1.5 & 90 & $4.9 \%$ & 1.4 & 70 & $4.7 \%$ & 1.1 \\
\hline Residential (C) & $1,020.0$ & $53.2 \%$ & 16.2 & 991 & $54.5 \%$ & 15.7 & 1,055 & $71.5 \%$ & 16.7 \\
\hline $\begin{array}{l}\text { Business and Personal } \\
\text { Services (D) }\end{array}$ & 94.0 & $4.9 \%$ & 1.5 & 92 & $5.1 \%$ & 1.5 & 38 & $2.6 \%$ & 0.6 \\
\hline Mercantile (E) & 83.3 & $4.3 \%$ & 1.3 & 78 & $4.3 \%$ & 1.2 & 33 & $2.2 \%$ & 0.5 \\
\hline Industrial (F) & 106.0 & $5.5 \%$ & 1.7 & 111 & $6.1 \%$ & 1.8 & 59 & $4.0 \%$ & 0.9 \\
\hline $\begin{array}{l}\text { Structures/properties not } \\
\text { classified by the Ontario } \\
\text { Building Code (G) }\end{array}$ & 108.0 & $5.6 \%$ & 1.7 & 71 & $3.9 \%$ & 1.1 & 75 & $5.1 \%$ & 1.2 \\
\hline Vehicles $(\mathrm{H})$ & 299.0 & $15.6 \%$ & 4.7 & 270 & $14.8 \%$ & 4.3 & 117 & $7.9 \%$ & 1.9 \\
\hline Total & $1,917.0$ & $100.0 \%$ & $\overline{30.4}$ & 1,819 & $100.0 \%$ & 28.9 & 1,476 & $100.0 \%$ & 23.4 \\
\hline
\end{tabular}


Table IV. Medical emergencies

\begin{tabular}{|c|c|c|c|c|c|c|c|c|}
\hline \multirow[t]{2}{*}{ 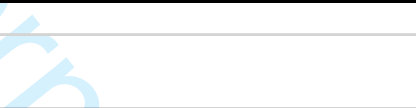 } & \multirow[b]{2}{*}{$\begin{array}{c}\text { \# of } \\
\text { Days }\end{array}$} & \multicolumn{3}{|c|}{ Preceding 3-Year Average } & \multicolumn{3}{|c|}{ COVID-19 Year } & \multirow[b]{2}{*}{$\begin{array}{r}\Delta \text { in No. } \\
\text { (in \%) }\end{array}$} \\
\hline & & $\begin{array}{c}\text { No. of } \\
\text { Incidents }\end{array}$ & $\begin{array}{l}\% \text { of Total } \\
\text { Incidents }\end{array}$ & $\begin{array}{l}\text { Average } \\
\text { No./Day }\end{array}$ & $\begin{array}{c}\text { No. of } \\
\text { Incidents }\end{array}$ & $\begin{array}{l}\% \text { of Total } \\
\text { Incidents }\end{array}$ & $\begin{array}{l}\text { Average } \\
\text { No./Day }\end{array}$ & \\
\hline Period 1 (17 March - 18 May) & 63 & 891.7 & $46.4 \%$ & 14.2 & 752 & $50.9 \%$ & 11.9 & $-15.7 \%$ \\
\hline Period 2 (19 May - 18 June) & 31 & 472.0 & $46.6 \%$ & 15.2 & 418 & $47.9 \%$ & 13.5 & $-11.4 \%$ \\
\hline Period 3 (19 June - 23 July) & 35 & 484.0 & $42.8 \%$ & 13.8 & 411 & $41.7 \%$ & 11.7 & $-15.1 \%$ \\
\hline Period 4 (24 July - 18 October) & 87 & $1,211.7$ & $43.7 \%$ & 13.9 & 1,169 & $47.4 \%$ & 13.4 & $-3.5 \%$ \\
\hline Period 5 (19 October - 13 December) & 56 & 807.7 & $46.5 \%$ & 14.4 & 806 & $51.3 \%$ & 14.4 & $-0.2 \%$ \\
\hline Period 6 (14 December - 13 January) & 31 & 494.3 & $48.8 \%$ & 15.9 & 518 & $60.7 \%$ & 16.7 & $4.8 \%$ \\
\hline Periods 1-6 & 303 & $4,361.3$ & $45.5 \%$ & 14.4 & 4,074 & $49.5 \%$ & 13.4 & $-6.6 \%$ \\
\hline
\end{tabular}

Table V. Medical emergencies by property type during Period 1

\begin{tabular}{|c|c|c|c|c|c|c|c|c|c|}
\hline \multirow[b]{2}{*}{ Property Type } & \multicolumn{3}{|c|}{ Average 2017-2019 } & \multicolumn{3}{|c|}{2019} & \multicolumn{3}{|c|}{2020} \\
\hline & $\begin{array}{l}\text { No. of } \\
\text { Incidents }\end{array}$ & (\%) & $\begin{array}{l}\text { Avg No. of } \\
\text { Incidents/ } \\
\text { Day }\end{array}$ & $\begin{array}{c}\text { No. of } \\
\text { Incidents }\end{array}$ & (\%) & $\begin{array}{l}\text { Avg No. of } \\
\text { Incidents/ } \\
\text { Day }\end{array}$ & $\begin{array}{c}\text { No. of } \\
\text { Incidents }\end{array}$ & (\%) & $\begin{array}{l}\text { Avg No. of } \\
\text { Incidents/ } \\
\text { Day }\end{array}$ \\
\hline Assembly (A) & 46.7 & 5.2 & 0.7 & 54 & 6.0 & 0.9 & 9 & 1.2 & 0.1 \\
\hline $\begin{array}{l}\text { Care and Detention } \\
\text { (B) }\end{array}$ & 64.7 & 7.3 & 1.0 & 64 & 7.1 & 1.0 & 47 & 6.3 & 0.7 \\
\hline Residential (C) & 606.7 & 68.1 & 9.6 & 637 & 70.5 & 10.1 & 623 & 82.8 & 9.9 \\
\hline $\begin{array}{l}\text { Business and Personal } \\
\text { Services (D) }\end{array}$ & 36.3 & 4.1 & 0.6 & 31 & 3.4 & 0.5 & 15 & 2.0 & 0.2 \\
\hline Mercantile (E) & 41.7 & 4.7 & 0.7 & 40 & 4.4 & 0.6 & 9 & 1.2 & 0.1 \\
\hline Industrial (F) & 33.0 & 3.7 & 0.5 & 32 & 3.5 & 0.5 & 17 & 2.3 & 0.3 \\
\hline $\begin{array}{l}\text { Structures/properties } \\
\text { not classified by the } \\
\text { Ontario Building Code } \\
\text { (G) }\end{array}$ & 28.3 & 3.2 & 0.4 & 20 & 2.2 & 0.3 & 21 & 2.8 & 0.3 \\
\hline Vehicles (H) & 34.0 & 3.8 & 0.5 & 25 & 2.8 & 0.4 & 11 & 1.5 & 0.2 \\
\hline Total & 891.3 & 100 & 14.1 & 903 & 100 & 14.3 & 752 & 100 & 11.9 \\
\hline
\end{tabular}

Table VI. Vehicle collisions/extrications

\begin{tabular}{|c|c|c|c|c|c|c|c|c|}
\hline & \multirow[b]{2}{*}{$\begin{array}{c}\text { \# of } \\
\text { Days }\end{array}$} & \multicolumn{3}{|c|}{ Preceding 3-Year Average } & \multicolumn{3}{|c|}{ COVID-19 Year } & \multirow[b]{2}{*}{$\begin{array}{r}\Delta \text { in No. } \\
\text { (in \%) }\end{array}$} \\
\hline & & $\begin{array}{c}\text { No. of } \\
\text { Incidents }\end{array}$ & $\begin{array}{l}\% \text { of Total } \\
\text { Incidents }\end{array}$ & $\begin{array}{l}\text { Average } \\
\text { No./Day }\end{array}$ & $\begin{array}{c}\text { No. of } \\
\text { Incidents }\end{array}$ & $\begin{array}{l}\% \text { of Total } \\
\text { Incidents }\end{array}$ & $\begin{array}{l}\text { Average } \\
\text { No./Day }\end{array}$ & \\
\hline Period 1 (17 March - 18 May) & 63 & 254.0 & $13.2 \%$ & 4.0 & 78 & $5.3 \%$ & 1.2 & $-69.3 \%$ \\
\hline Period 2 (19 May - 18 June) & 31 & 143.7 & $14.2 \%$ & 4.6 & 78 & $8.9 \%$ & 2.5 & $-45.7 \%$ \\
\hline Period $3(1$ & 35 & 177.0 & $.7 \%$ & 5.1 & 83 & $8.4 \%$ & 2.4 & $-53.1 \%$ \\
\hline Period 4 (24 July - 18 October) & 87 & 423.3 & $15.3 \%$ & 4.9 & 278 & $11.3 \%$ & 3.2 & $-34.3 \%$ \\
\hline Period 5 (19 October - 13 December) & 56 & 291.0 & $16.7 \%$ & 5.2 & 171 & $10.9 \%$ & 3.1 & $-41.2 \%$ \\
\hline Period 6 (14 December - 13 January) & 31 & 143.7 & $14.2 \%$ & 4.6 & 59 & $6.9 \%$ & 1.9 & $-58.9 \%$ \\
\hline Periods 1-6 & 303 & $1,432.7$ & $14.9 \%$ & 4.7 & 747 & $9.1 \%$ & 2.5 & $-47.9 \%$ \\
\hline
\end{tabular}


Table VII. False fire calls

\begin{tabular}{|c|c|c|c|c|c|c|c|c|}
\hline \multirow{2}{*}{$P_{2}$} & \multirow[b]{2}{*}{$\begin{array}{c}\text { \# of } \\
\text { Days }\end{array}$} & \multicolumn{3}{|c|}{ Preceding 3-Year Average } & \multicolumn{3}{|c|}{ COVID-19 Year } & \multirow[b]{2}{*}{$\begin{array}{r}\Delta \text { in No. } \\
\text { (in } \%)\end{array}$} \\
\hline & & $\begin{array}{c}\text { No. of } \\
\text { Incidents }\end{array}$ & $\begin{array}{l}\% \text { of Total } \\
\text { Incidents }\end{array}$ & $\begin{array}{l}\text { Average } \\
\text { No./Day }\end{array}$ & $\begin{array}{c}\text { No. of } \\
\text { Incidents }\end{array}$ & $\begin{array}{l}\% \text { of Total } \\
\text { Incidents }\end{array}$ & $\begin{array}{l}\text { Average } \\
\text { No./Day }\end{array}$ & \\
\hline Period 1 (17 March - 18 May) & 63 & 321.7 & $16.7 \%$ & 5.1 & 205 & $13.9 \%$ & 3.3 & $-36.3 \%$ \\
\hline Period 2 (19 May - 18 June) & 31 & 138.3 & $13.7 \%$ & 4.5 & 132 & $15.1 \%$ & 4.3 & $-4.6 \%$ \\
\hline Period 3 (19 June - 23 July) & 35 & 189.0 & $16.7 \%$ & 5.4 & 195 & $19.8 \%$ & 5.6 & $3.2 \%$ \\
\hline Period 4 (24 July - 18 October) & 87 & 473.3 & $17.1 \%$ & 5.4 & 408 & $16.5 \%$ & 4.7 & $-13.8 \%$ \\
\hline Period 5 (19 October - 13 December) & 56 & 270.0 & $15.5 \%$ & 4.8 & 242 & $15.4 \%$ & 4.3 & $-10.4 \%$ \\
\hline Period 6 (14 December - 13 January) & 31 & 163.0 & $16.1 \%$ & 5.3 & 99 & $11.6 \%$ & 3.2 & $-39.3 \%$ \\
\hline Periods 1-6 & 303 & $1,555.3$ & $16.2 \%$ & 5.1 & 1,281 & $15.6 \%$ & 4.2 & $-17.6 \%$ \\
\hline
\end{tabular}

Table VIII. Controlled burning incidents

\begin{tabular}{|c|c|c|c|c|c|c|c|c|}
\hline & \multirow[b]{2}{*}{$\begin{array}{c}\text { \# of } \\
\text { Days }\end{array}$} & \multicolumn{3}{|c|}{ Preceding 3-Year Average } & \multicolumn{3}{|c|}{ COVID-19 Year } & \multirow[b]{2}{*}{$\begin{array}{r}\Delta \text { in No. } \\
\text { (in \%) }\end{array}$} \\
\hline & & $\begin{array}{c}\text { No. of } \\
\text { Incidents }\end{array}$ & $\begin{array}{l}\% \text { of Total } \\
\text { Incidents }\end{array}$ & $\begin{array}{l}\text { Average } \\
\text { No./Day }\end{array}$ & $\begin{array}{c}\text { No. of } \\
\text { Incidents }\end{array}$ & $\begin{array}{l}\% \text { of Total } \\
\text { Incidents }\end{array}$ & $\begin{array}{l}\text { Average } \\
\text { No./Day }\end{array}$ & \\
\hline Period 1 (17 March - 18 May) & 63 & 21.7 & $1.1 \%$ & 0.3 & 54 & $3.7 \%$ & 0.9 & $149.2 \%$ \\
\hline Period 2 (19 May - 18 June) & 31 & 15.7 & $1.5 \%$ & 0.5 & 45 & $5.2 \%$ & 1.5 & $187.2 \%$ \\
\hline Periods 1-2 & 94 & 37.3 & $1.3 \%$ & 0.1 & 99 & $4.2 \%$ & 0.3 & $165.2 \%$ \\
\hline
\end{tabular}

Table IX. Property fires/explosions

\begin{tabular}{|c|c|c|c|c|c|c|c|c|}
\hline & \multirow[b]{2}{*}{$\begin{array}{c}\text { \# of } \\
\text { Days }\end{array}$} & \multicolumn{3}{|c|}{ Preceding 3-Year Average } & \multicolumn{3}{|c|}{ COVID-19 Year } & \multirow[b]{2}{*}{$\begin{array}{r}\Delta \text { in No. } \\
\text { (in \%) }\end{array}$} \\
\hline & & $\begin{array}{c}\text { No. of } \\
\text { Incidents }\end{array}$ & $\begin{array}{l}\% \text { of Total } \\
\text { Incidents }\end{array}$ & $\begin{array}{l}\text { Average } \\
\text { No./Day }\end{array}$ & $\begin{array}{c}\text { No. of } \\
\text { Incidents }\end{array}$ & $\begin{array}{l}\% \text { of Total } \\
\text { Incidents }\end{array}$ & $\begin{array}{l}\text { Average } \\
\text { No./Day }\end{array}$ & \\
\hline Period 1 (17 March - 18 May) & 63 & 54.7 & $2.8 \%$ & 0.9 & 52 & $3.5 \%$ & 0.8 & $-4.9 \%$ \\
\hline Period 2 (19 May - 18 June) & 31 & 37.3 & $3.7 \%$ & 1.2 & 32 & $3.7 \%$ & 1.0 & $-14.3 \%$ \\
\hline Period 3 (19 June - 23 July) & 35 & 35.3 & $3.1 \%$ & 1.0 & 45 & $4.6 \%$ & 1.3 & $27.4 \%$ \\
\hline Period 4 (24 July - 18 October) & 87 & 70.0 & $2.5 \%$ & 0.8 & 68 & $2.8 \%$ & 0.8 & $-2.9 \%$ \\
\hline Period 5 (19 October - 13 December) & 56 & 32.0 & $1.8 \%$ & 0.6 & 28 & $1.8 \%$ & 0.5 & $-12.5 \%$ \\
\hline Period 6 (14 December - 13 January) & 31 & 17.3 & $1.7 \%$ & 0.6 & 11 & $1.3 \%$ & 0.4 & $-36.4 \%$ \\
\hline Periods 1-6 & 303 & 246.6 & $2.6 \%$ & 0.8 & 236 & $2.9 \%$ & 0.8 & $-4.3 \%$ \\
\hline
\end{tabular}


Table A. Property type categories

\begin{tabular}{|c|c|c|}
\hline \multirow{8}{*}{ Group A } & \multirow{8}{*}{ Assembly } & Production/Viewing performing arts \\
\hline & & Museum/Art gallery/Auditorium \\
\hline & & Recreation/sports facility \\
\hline & & Education facility \\
\hline & & Transportation Facility \\
\hline & & Other assembly \\
\hline & & Arenas/Swimming pools \\
\hline & & Participating/Viewing open air facilities \\
\hline \multirow{6}{*}{ Group B } & \multirow{6}{*}{ Care and Detention } & Persons under restraint \\
\hline & & Persons under supervisory care \\
\hline & & Care facility \\
\hline & & Transitional shelter \\
\hline & & Group/Retirement Home \\
\hline & & Other Care and Detention \\
\hline \multirow{7}{*}{ Group C } & \multirow{7}{*}{ Residential } & Detached/semi/attached residential \\
\hline & & Dual Residential/Business \\
\hline & & Rooming/Boarding \\
\hline & & Multi unit dwelling \\
\hline & & Seasonal dwelling/Mobile home \\
\hline & & Hotel/Motel/Lodging \\
\hline & & Other residential \\
\hline \multirow{2}{*}{ Group D } & \multirow{2}{*}{ Business and Personal Services } & Business and Personal Services \\
\hline & & Other Business/personal services \\
\hline \multirow{4}{*}{ Group E } & \multirow{4}{*}{ Mercantile } & Food/beverage sales \\
\hline & & Department store/catalogue/mail outlet \\
\hline & & Specialty stores \\
\hline & & Other mercantile \\
\hline \multirow{5}{*}{ Group F } & \multirow{5}{*}{ Industrial } & Vehicle sales/service \\
\hline & & Utilities \\
\hline & & Manufacturing or processing \\
\hline & & Storage \\
\hline & & Other Industrial \\
\hline \multirow{8}{*}{ Group G } & \multirow{8}{*}{$\begin{array}{l}\text { Structures/Properties not } \\
\text { classified by the Ontario } \\
\text { Building Code }\end{array}$} & Mine/Well \\
\hline & & Transportation Facility \\
\hline & & Communications facility \\
\hline & & Open (outdoor) storage \\
\hline & & Miscellaneous structure \\
\hline & & Miscellaneous property \\
\hline & & Classed under National Farm Building Code \\
\hline & & Other Miscellaneous property, structure \\
\hline \multirow{5}{*}{ Group H } & \multirow{5}{*}{ Vehicles } & Road vehicles \\
\hline & & Rail vehicles \\
\hline & & Watercraft \\
\hline & & Aircraft \\
\hline & & Miscellaneous/specialty vehicle \\
\hline
\end{tabular}

Note: The last two categories (Structures/Properties not classified by the Ontario Building Code and Vehicles) are not actually assigned group letters in the Standard Incident Report Codes List. For ease of reference in Figures, Tables, and the discussion in this paper, these two property type categories are referred to as Groups $\mathrm{G}$ and $\mathrm{H}$, respectively.

Source: Standard Incident Report Codes List (Office of the Fire Marshal of Ontario, 2009) 